\title{
Simulating the effects of cool roof and PCM (phase change materials) based roof to mitigate UHI (urban heat island) in prominent US cities
}

\author{
Q2 K. Roman ${ }^{\mathrm{a},{ }^{*}, \text { T. O'Brien }}{ }^{\mathrm{b}}$, J. Alvey ${ }^{\mathrm{a}}$, J. Oh ${ }^{\mathrm{a}}$ \\ a Department of Mechanical Science and Engineering, University of Illinois at Urbana-Champaign, United States
}

${ }^{\mathrm{b}}$ Department of Mechanical Engineering, Virginia Tech, United States

\section{A R T I C L E I N F O}

\section{Article history:}

Received 8 July 2015

Received in revised form

22 October 2015

Accepted 28 November 2015

Available online $\mathrm{xxx}$

\section{Keywords:}

Cool roofs

PCM roofs

Envelope materials

Urban heat island

Sensible heat

Roof surface temperature

\begin{abstract}
A B S T R A C T
UHI (Urban Heat Island) has become a serious concern within major cities due to the increased threat of climate change over time. As UHI intensifies, the energy consumed in urban areas increases through an increase in the cooling demand, and restricts the overall comfort and quality of life in urban regions. UHI mitigation approaches have been widely studied over the past few decades. However, the work presented here evaluates and compares how PCM (cool roof and phase change materials) based roof technologies may perform as UHI mitigation strategies. Detailed thermal energy simulations were conducted with these two strategies over a range of seven climatic zones within the United States. For each mitigation strategy, five different roof types were chosen for the analysis. The results indicate that a higher albedo led to superior energy saving and UHI mitigation for all types of roofing materials. Also, asphalt roofs produced the best results of all the roof types. It was found that insulation did not play a significant role in the reduction of UHI effects. The maximum TRHG (through roof heat gain) flux was 54\% lower for the PCM roof than the cool roof at a wide range of albedo. Similarly, the maximum sensible heat flux for the PCM roof type $40 \%$ lower than the cool roof technology for varying albedo.
\end{abstract}

(C) 2015 Published by Elsevier Ltd.

\section{Introduction}

The heat island effect describes how densely packed urban areas are warmer than in surrounding rural regions. Densely positioned buildings and structures within urban areas absorbing solar radiation in the form of heat, a lack of vegetation or green space, and the heat generated from environmental pollution are all direct contributors towards this urban heat phenomena. This issue affects the majority of the population within the United States of America. The United Nations Population Division reported that in United States of America urban population was approximately $81.4 \%$ for the year of 2014 and estimated that the urban population will continue to increase to $87.4 \%$ by the year 2050 [1].

For decades, researchers have studied UHI (Urban Heat Island) effects [2-8], and still the main mitigation concept was conceived during ancient Greek times [9]. The use of materials with a high solar reflectance (albedo) for roofs within urban regions can significantly affect the micro-climate of an urban area, mostly due to the large surface area of roofs within urban areas [10]. Akabari

\footnotetext{
* Corresponding author. Tel.: +1 2178191775.

E-mail address: mgkhan2@illinois.edu (K. Roman).
}

et al. [11] estimated a roof surface area as high as $25 \%$ in densely populated cities within the United States. Thus, the technological advancement of cool materials, or materials with high solar reflectance and infrared emittance, has been a continued effort around the world. Cool material technology presents a costeffective, environmentally friendly, passive technique that can significantly impact the energy consumption of individual buildings, as well as the overall climate of urban areas $[12,13]$. The primary objective of cool or reflective roof technology is to increase the albedo. Typically, this is done by applying a liquid material (white paint, elastomeric, polyurethane, acrylic coatings), or by using single ply product (Ethylene-Propylenediene-Tetrolymer Membrane, Polyvinyl Chloride, Chlorinated Polyethylene, Chlorosulfonated Polyethylene, Thermoplastic Polyolefin) [9]. However, this technique has evolved over the years as more and more highly reflective materials are discovered. Most recently, advances in nanotechnology has lead to the conception of highly reflective thermochromatic paint [14]. Thermochromatic paints are designed to be thermally reversible, meaning that during the hot summer months the cool roof will have a high reflectivity and during the cold winters, a high absorption rate. Although currently more expensive, this technology does present a significant advantage 


\begin{tabular}{|c|c|c|c|}
\hline \multicolumn{2}{|c|}{ Nomenclature } & $T_{a}$ & outside air dew-point temperature \\
\hline C & specific heat & & temperature and outside air temperature \\
\hline$G r_{L_{n}}$ & Grashof number, $g \rho^{2} L_{n}^{3} \Delta T / T_{f} \mu^{2}$ & $T_{r}$ & roof outside surface temperature \\
\hline$g$ & gravitational constant & $x$ & distance along wind direction from roof edge to \\
\hline$h_{r}$ & heat transfer coefficient & & convection coefficient evaluation point \\
\hline$k$ & conductivity of air & $x_{c}$ & critical length \\
\hline$L_{n}$ & $\begin{array}{l}\text { characteristic length for natural convection, } \\
\text { (area-to-perimeter ratio) }\end{array}$ & $\begin{array}{l}u \\
\Delta T\end{array}$ & $\begin{array}{l}\text { free-stream wind speed at roof level } \\
\text { roof outside surface temperature minus outside air }\end{array}$ \\
\hline $\mathrm{Nu}$ & Nusselt number & & temperature \\
\hline $\operatorname{Pr}$ & Prandtl number & $\beta$ & weighting factor for natural convection \\
\hline$q_{r, s}$ & sensible heat flux & $\mu$ & viscosity of air evaluated at $T_{f}$ \\
\hline$q_{r, g}$ & through roof heat gains flux & $\rho$ & density of air evaluated at $T_{f}$ \\
\hline$R a$ & Rayleigh number & $\varepsilon$ & emissivity \\
\hline $\operatorname{Re}_{x}$ & Reynolds number & HVAC & heating, ventilation, and air conditioning \\
\hline$R_{f}$ & surface roughness factor & TRHG & through roof heat gains \\
\hline
\end{tabular}

over its competitors [14]. However, another mitigation technique (i.e. PCM (phase change materials) roof), while not nearly as longstanding as the "cool roof" technology, provides an alternative solution. PCM possesses high latent heat capacity that makes it feasible to use as an energy storage media in building envelope.

The use of PCM for thermal energy storage was introduced around the 1980s [15]. More recently, the use of PCM has been experimented within the envelope of the roof in an attempt to reduce energy consumption [16], [17]. PCM can be enclosed within the roofs of buildings which might play a large role towards thermal balance. These materials absorb solar and infrared radiation and release a portion of the accrued thermal energy through convective and radiative processes into the atmosphere. PCM can be sub-divided into three main categories based on the chemical structure (organic, inorganic, and eutectic mixtures) [18]. Fundamentally, PCM technology partially absorbs cool energy from air conditioning systems or free cooling (storage of cool energy overnight) and helps to maintain that temperature throughout the peak hours of the day, thereby increasing thermal comfort [19]. The chemicals within the PCM undergo a cycle of phase changes to continually reduce the effect of outdoor temperatures on indoor temperatures, delay the peak heat loads, as well as stabilizing the interior temperature [20]. PCM does this not by affecting the thermal resistance of a roof, but rather by influencing the surface temperature [18]. While increasing the albedo of a roof will reduce the cooling load of buildings, there may be a potential need for an increase in heating needs over the course of winter.

The effects of roof technology on UHI result from an interplay of several causes. Absorption of short-wave solar radiation, anthropogenic heat released from the built environment, a decrease in latent heat due to lack of moisture sorption in urban materials, and change in urban forms are all contributing factors to UHI [21-23]. The roof technologies studied in the present work can affect one or multiple of these causes. Both cool roof and PCM roof can help to decrease the cooling load demand. The cool roof approach can reduce the amount of absorbed radiation, and the PCM approach can reduce the sensible heat by introducing latent heat gains of the PCM. Three metrics were chosen to help monitor the effectiveness of the various roof types that incorporate these technologies: TRHG (through roof heat gain) flux, roof surface temperature, and sensible heat flux.

In the work reported here, thermal energy modeling was utilized over a wide range of climatic zones across the United States of America to determine the effectiveness of cool roof vs. PCM roof technologies in mitigating UHI effects. Roof surface temperature, thermal energy entering the room via the roof, and sensible heat flux were analyzed at these different climatic regions. These thermal measurements were again examined with various PCM materials within the envelope of the roof. Metal, concrete, built-up (combination of tar and gravel), asphalt shingles, and Single Ply Membrane roof types were the cool roof types that were evaluated within the analysis, while BioPCM, Enerciel22, $\mathrm{CaCl} .6 \mathrm{H}_{2} 0$, Eutectic salt and Paraffin were the various types of PCM roof materials evaluated. Lastly, a parametric analysis was performed on the effects of albedo on PCM variations and roofing materials. The goal of this research was to enlighten a large and thermally diverse nation of improved approaches towards reducing commercial and industrial energy costs.

\section{Methodology}

\subsection{Simulation}

In this study, dynamic thermal behavior for various roof types was simulated within DesignBuilder, a graphical interface coupled with the popular EnergyPlus energy simulation software. EnergyPlus is frequently used to model and simulate building energy consumption. It has the capability to accurately model the energy flow between a building and its environment. Unfortunately, the required level of expertise for EnergyPlus is a significant hurdle for nontechnical users mainly due to the many intricate decisions that are required to produce an accurate model. Fortunately DesignBuilder provides a wide breadth of features that enables a more user-intimate environment. DesignBuilder was designed around EnergyPlus, and thus still uses EnergyPlus as its heat simulation engine. This powerful software was largely used to calculate and graphically illustrate the sensible heat flux, surface temperature and heat gain incident on the roof for various cool/reflective materials.

\subsection{Building model}

The DOE (Department of Energy) has graciously provided fifteen 'benchmark building' files for public usage within the EnergyPlus simulation environment [24]. These models, although extremely convenient for simple simulations, lack the necessary detail to reflect the intricacies of a commercial/industrial building. To improve the resolution and detail of the system, a typical hospital building floor plan was used as a reference to model a more commonly seen edifice. This is much more detailed than a standard 
Cool Roof Solar Reflectivity

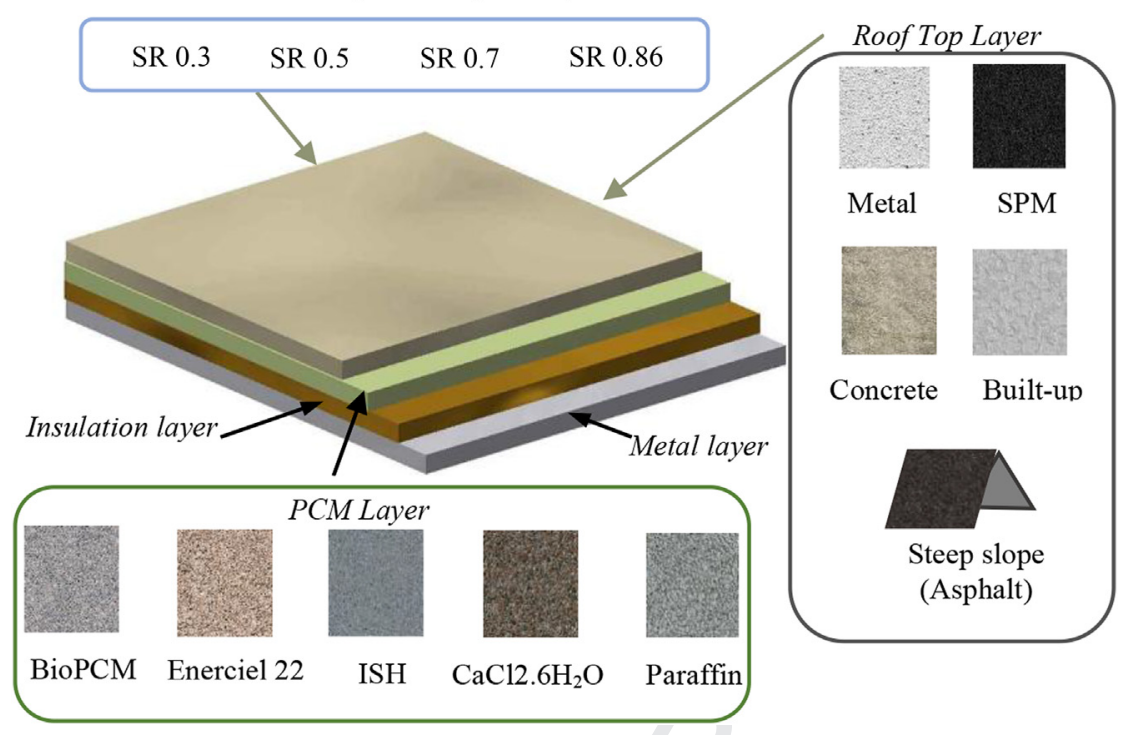

Fig. 1. This illustration provides a detailed graphical explanation of the various types of materials that were incorporated throughout this thermal simulation study.

Table 1

Reference building characteristics used for EnergyPlus simulations.

\begin{tabular}{lll}
\hline Types & Characteristics & Descriptions \\
\hline Forms & Building type & Hospital \\
& Surface area & $1080 \mathrm{~m}^{2}$ \\
Envelope & Orientation & E-W \\
& Walls & Stucco, Insulation, gypsum board, total $\mathrm{U}=2.53 \mathrm{~W} / \mathrm{m}^{2}-\mathrm{K}, \mathrm{surface}$ area $2063 \mathrm{~m}^{2}$ \\
& Roof & Roof membrane, insulation, metal decking, total $\mathrm{U}=3.45 \mathrm{~W} / \mathrm{m}^{2}-\mathrm{K}$, surface area $560 \mathrm{~m}^{2}$ \\
& Floor & Concrete floor with carpet, $\mathrm{U}=1.94 \mathrm{~W} / \mathrm{m}^{2}-\mathrm{K}$ \\
$\mathrm{HVAC}$ & Windows & ECREF-2 colored glass windows, total $\mathrm{U}=3.43 \mathrm{~W} / \mathrm{m}^{2}-\mathrm{K}$, surface area $119 \mathrm{~m}^{2}$ \\
& Heating type & Gas furnace inside the packaged air conditioning unit \\
& Cooling type & Packaged air conditioning unit \\
& Distribution and terminal units & VAV terminal box with damper and electric reheating coil \\
\hline
\end{tabular}

box-like structure. Also, a hospital floor plan makes sense to use as it is the type of facility in which a great deal of time and care would have gone into managing the amount of energy consumed throughout the year. Further detail was implemented via the manual creation of various types of roofs within DesignBuilder. Fig. 1 illustrates some of the roof designs that were utilized within this study. Several different rooftop materials were considered along with several different PCM materials. The steep slope rooftop was chosen to be asphalt shingles which represents the most common material for steep slopes.

Detailed specification of the two-level hospital building including building surface area, orientation, building envelope features and HVAC system setting are tabulated in Table 1. Thermostat settings and operation schedules were taken from DOE benchmark building information. As mentioned before the simulation was conducted by using DesignBuilder. However to better visualize the floor plans and 3D model, which is shown in Figs. 2-4, a commercial software Revit was used to depict the same model as it was used in DesignBuilder. During the simulation all the building features were kept constant except only designated roof type was changed. It should be noted that the modeling and building characteristics outlined in this paper can be used to any residential or commercial building prototype.

\subsection{Climate data}

Energy consumption within urban areas is expected to increase during the summer months. The days that yield the highest ambient temperature and the strongest solar radiation naturally equate to the days that yield the greatest amount of energy consumed. Typically, the seven hottest days of summer range from July 23rd through July $30^{\text {th }}$. An analysis of the energy consumed on these particularly hot days could lead to the curtailing of energy consumption related expenses in buildings within urban regions. However, when comparing the thermal effects of urban regions across a country as large and climatically diverse as the United States, it's important to take into account the climate difference

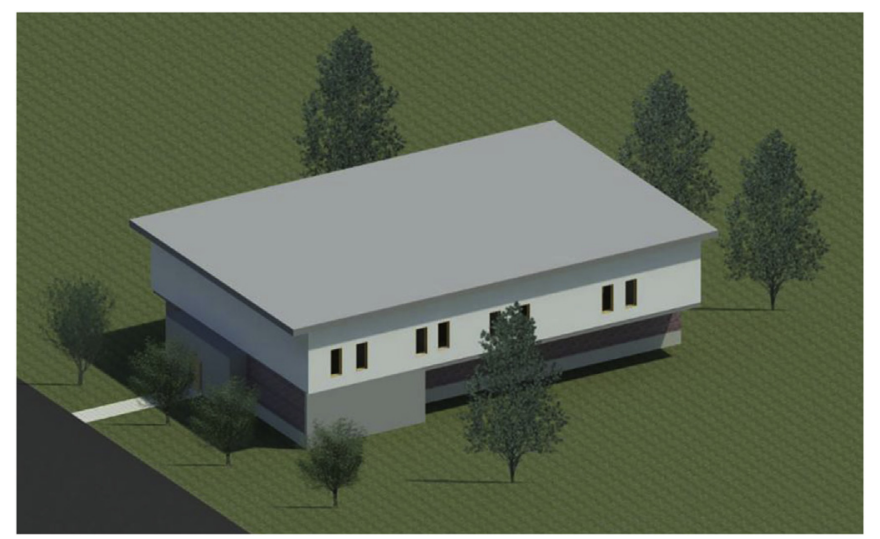

Fig. 2. A 3D rendering of the building considered in this study, created in Revit. It is a two level hospital-type floor plan. 


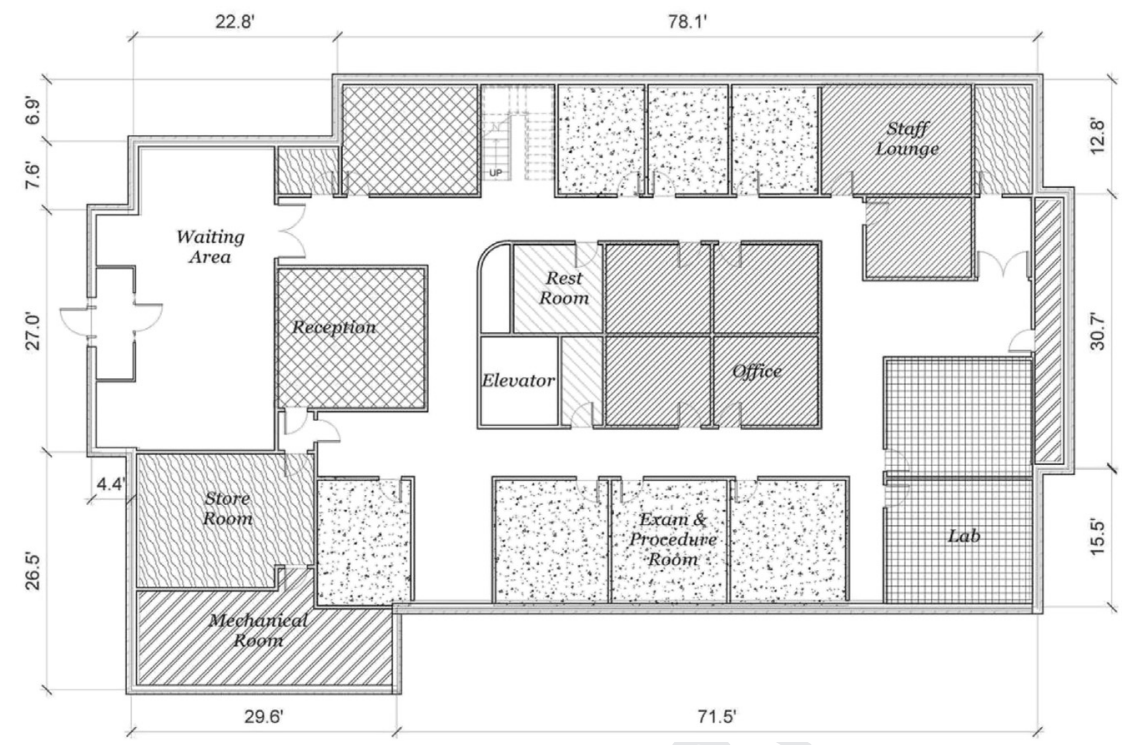

Fig. 3. The ground-floor plan of the building considered in this study, showing dimensions and intended uses, for simulation in DesignBuilder software.

between the regions of interest. Thus, in an effort to account for this, cities from varying climate zones were taken into consideration. Fig. 5 illustrates a climate zone mapping of the United States [25], while Table 2 shows seven major cities within each climatic region. Designbuilder simulation results were collected in 30-min intervals over the seven warm days of the summer (July 23rd to July 30th). From this table, each city was used for thermal simulations. For each major city that was considered, the sensible heat flux, TRHG flux, and roof surface temperature for a variation of albedo, roof types, insulation, and PCM were recorded.

\subsection{Heat transfer theory}

Although EnergyPlus is vastly popular, and powerful, it's method for solving the heat transfer coefficient at a particular point on a roof only takes into consideration when the air above the roof is turbulent due to natural convection. Clear et al. [26] went a step further and mathematically explained the case for when the air above the roof does not produce turbulence. Although this may be a less common occurrence, it could happen and thus should be accounted for $[26,27]$. Sensible heat flux refers to the convective heat flux from the roof surface to the ambient air can be described by equation (1).

$q_{r, s}=h_{r}\left(T_{r}-T_{a}\right)$

where, $T_{a}$ is the ambient air temperature which can be found from the TMY3 weather file for different US cities [28] and $T_{r}$ is the roof surface temperature which was found from the simulation results of Designbuilder software.

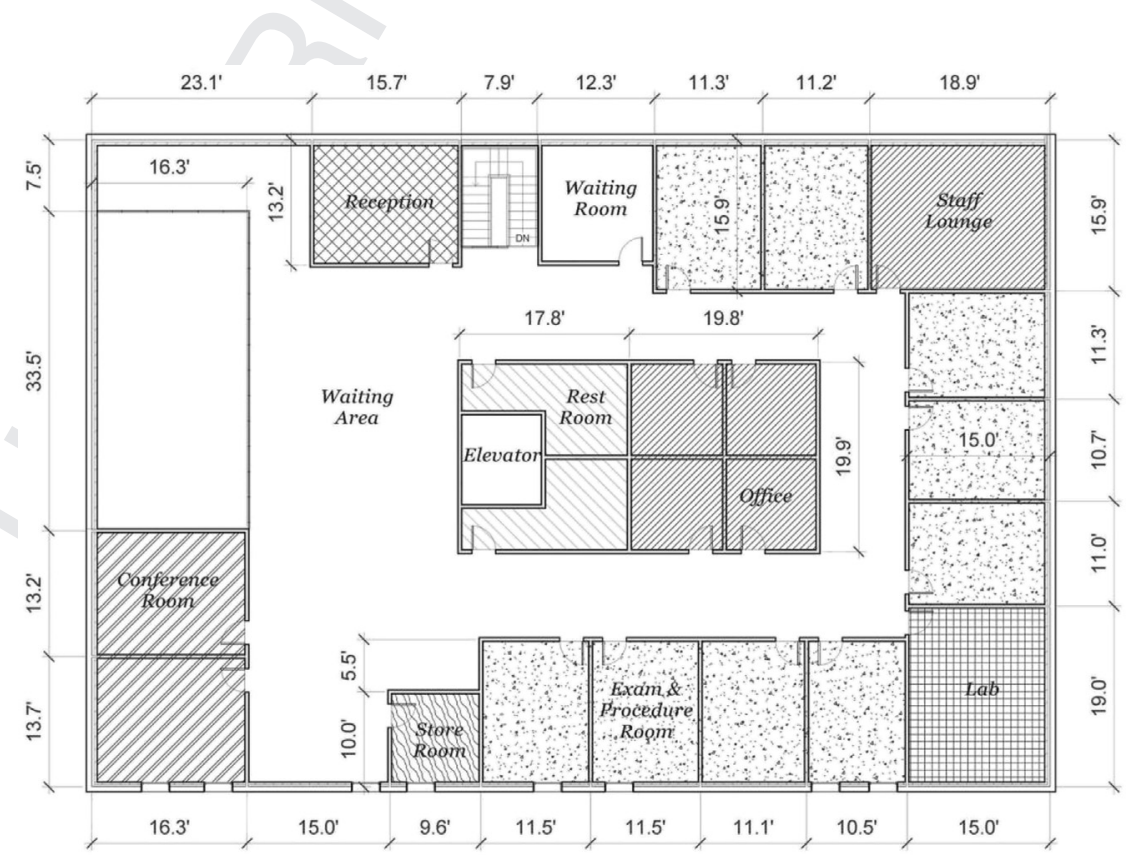

Fig. 4. The first-floor plan of the building considered in this study, showing dimensions and intended uses, for simulation in DesignBuilder software. 


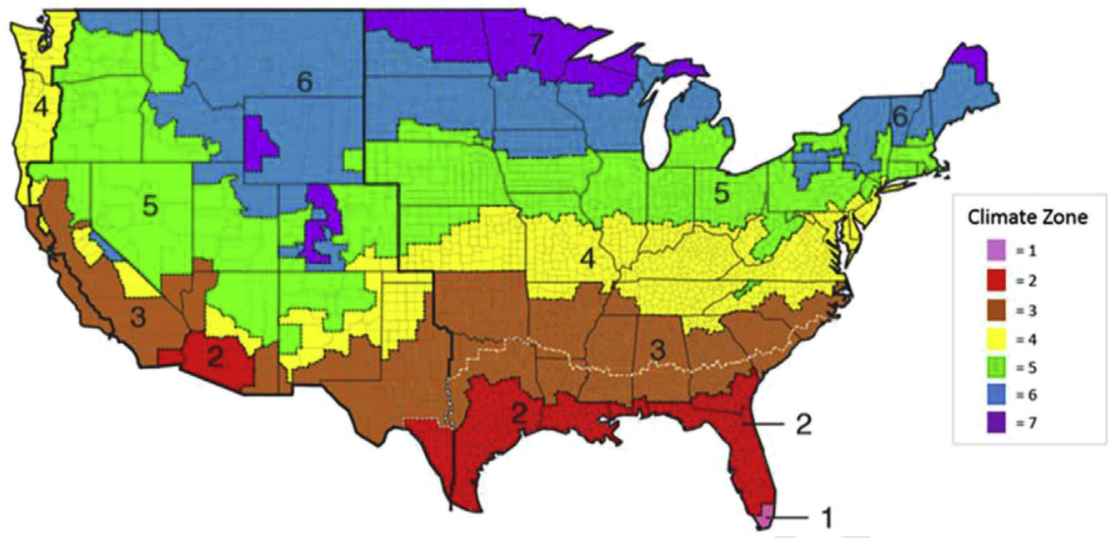

Fig. 5. This map of the United States indicates the seven different climatic regions [25].

Equations used to solve for the heat transfer coefficient, $h_{r}$, were based on standard convection heat flow relationships. These empirical relationships, found in Table 3, describe flow over a

$$
R a=G r_{L_{n}} P r
$$
smooth, isothermal flat plate with its upper surface being cooled or heated, were used to decide the flow condition and Eq. (2) was used to calculate heat transfer coefficient.

The combination of the natural and forced Nusselt numbers led to equation (2) for the heat transfer coefficient [26],s

$$
G r_{L_{n}}=\frac{g \rho^{2} L_{n}^{3} \Delta T}{T_{f} \mu^{2}}
$$

$$
h_{r}=\left\{\begin{array}{c}
\beta \frac{k}{L_{n}} 0.15 R a_{L_{n}}^{1 / 3}+\frac{k}{x} R_{f} 0.037 \operatorname{Re}_{x}^{4 / 5} \operatorname{Pr}^{1 / 3} \quad \text { When, } T_{r}-T_{a} \geq 0 \\
\beta \frac{k}{L_{n}} 0.27 R a_{L_{n}}^{1 / 4}+\frac{k}{x} R_{f} 0.66 \operatorname{Re}_{x}^{1 / 2} \operatorname{Pr}^{1 / 3} \quad \text { When, } T_{r}-T_{a}<0 \text { and } x<x_{c} \\
\beta \frac{k}{L_{n}} 0.27 R a_{L_{n}}^{1 / 4}+\frac{k}{x} R_{f}\left(0.0037 \operatorname{Re}_{x}^{4 / 5}-871\right) \operatorname{Pr}^{1 / 3} \quad \text { When, } T_{r}-T_{a}<0 \text { and } x>x_{c}
\end{array}\right.
$$

where, $\beta$ is a function which describes the relationship between the Grashof and Reynolds numbers, as shown in equation (3).

$\beta=\frac{\ln \left(1+G r_{L_{n}} / \operatorname{Re}_{\chi}^{2}\right)}{1+\ln \left(1+G r_{L_{n}} / \operatorname{Re}_{\chi}^{2}\right)}$

The Reynolds number, Rayleigh number and Grashof number are described in equations (4)-(6) respectively.

$\operatorname{Re}_{x}=\frac{u \rho X}{\mu}$

Table 2

Climate zones and their respective major cities.

\begin{tabular}{lll}
\hline Climate zone & Climate type & Corresponding major city \\
\hline 1 & Hot-humid & Miami, FL \\
2 & Hot-humid & Houston, TX \\
3 & Hot-dry & Los Angeles, CA \\
4 & Marine & Seattle, WA \\
5 & Cold & Chicago, IL \\
6 & Cold & Minneapolis, MN \\
7 & Very cold & Fargo, ND \\
\hline
\end{tabular}

\section{Results and discussion}

\subsection{Cool roof}

\subsubsection{Effect of albedo variation}

Thermal energy modeling was applied to determine heat generation within a typical hospital building. Standard cool roof Sensible Reflectivity (SR), Emissivity ( $\varepsilon$ ), and SRI (solar radiation index) values were gathered from the Cool Roof Rating Council to be utilized within the simulations. Table 4 shows these optical properties for the cool roof based on built-up roof type.

Sensible heat flux, $q_{r, s}$ (i.e. heat flux from roof surface to the surrounding environment), TRHG flux, $q_{r, g}$ (i.e. heat flux to building

Table 3

Flat plate convective heat flow correlations [26].

\begin{tabular}{lll}
\hline Convection type & Range & Nusselt number $(\mathrm{Nu})$ \\
\hline Natural & $\Delta T>0,10^{7}<R a<10^{10}$ (turbulent) & $0.15 \operatorname{Ra}^{1 / 3}$ \\
& $\Delta T<0,10^{5}<R a<10^{10}$ & $0.27 \operatorname{Ra}^{1 / 4}$ \\
Forced & $\operatorname{Re}<10^{5}($ laminar) & $0.332 \operatorname{Re}_{x}^{1 / 2} \operatorname{Pr}^{1 / 3}$ \\
& $10^{5}<\operatorname{Re}<10^{8}$ (turbulent) & $0.0296 \operatorname{Re}_{x}^{4 / 5} \operatorname{Pr}^{1 / 3}$ \\
\hline
\end{tabular}


Table 4

Optical properties of built-up roofs used for simulation.

\begin{tabular}{lllcll}
\hline Roof type & SR & $\varepsilon$ & SRI & Color & Vendor/Source \\
\hline Built-up Roof & 0.3 & 0.9 & $31.8^{\text {a }}$ & Bright White & {$[29]$} \\
& 0.5 & 0.86 & 57 & & {$[30]$} \\
& 0.7 & 0.91 & 86 & & {$[31]$} \\
& 0.86 & 0.82 & 107 & & {$[32]$} \\
\hline
\end{tabular}

$\overline{\text { Cool roof properties are taken from CRRC [30] and DOE medium office benchmark }}$ model [33].

a SRI value was calculated by using ORNL SRI Calculator (ASTM E1980-01).

interior through the roof), and roof surface temperature, $T_{r}$ were analyzed for the hospital building with various albedo values over a $24 \mathrm{~h}$ time interval during the hottest week of the summer. Sensible heat flux values were calculated by using Eqs. 1-6 and it accounts both the effect of forced and natural convection depending on the climatic condition. TRHG flux and roof surface temperatures were extracted directly from the simulation results. Additionally, TRHG flux was repeated for seven climatically diverse cities across the United States and then averaged at the peak hours to compare the results across each representative city. Fig. 6 provides a graphical sampling of the collected data. Fig. 6A shows the TRHG flux for Miami, Florida at varying levels of albedo. For this particular example, the greatest value of TRHG flux was $54.50 \mathrm{~W} / \mathrm{m}^{2}$, exhibited by the solar reflectivity of 0.3 . As solar reflectivity of the roof type increased, the TRHG flux steadily decreased. Fig. 6B and C illustrate the roof surface temperature and sensible heat flux for varying levels of solar reflectivity respectively. Similar to the TRHG flux plot, there is an analogous relationship in both surface temperature and sensible heat flux with solar reflectivity. Lastly, Fig. 6D shows the TRHG flux recorded for the seven cities (Miami, Chicago, Houston, Los Angeles, Minneapolis, Seattle, and Fargo). The average peak TRHG flux was higher for roofs with a lower solar reflectivity, regardless of the region. However, the average peak TRHG flux was the greatest in the southeastern region of the United States and lowest in the northwestern region. This could be attributed to geographical distance from the equator or cool winds blowing from the Pacific Ocean. Moreover in Fig. 6D it can be seen that in Los Angeles (e.g. a hot and dry climatic region) the difference of TRHG flux in between two extreme albedo (SR 0.3 and 0.86 ) roofing materials is $31.2 \mathrm{~W} / \mathrm{m}^{2}$, highest among all cites. Whereas in Miami and Houston (e.g. a hot and humid climatic region) the difference of TRHG flux are $19.1 \mathrm{~W} / \mathrm{m}^{2}$ and $15.7 \mathrm{~W} / \mathrm{m}^{2}$ respectively. From these results it can be inferred that humidity might have detrimental effects on both the energy saving and UHI mitigation especially for higher albedo roofing materials in hot climatic regions. It is also noticeable that for cold climatic regions like, Chicago, Minneapolis, and Fargo, the difference of TRHG flux between the two most extreme albedo values (SR 0.3 and 0.86 ) were $28 \mathrm{~W} / \mathrm{m}^{2}, 23.5 \mathrm{~W} / \mathrm{m}^{2}$, and $24.1 \mathrm{~W} / \mathrm{m}^{2}$ respectively, which processes very similar behavior in energy saving and UHI mitigation.

A high albedo on the roof surface could potentially improve the lifetime of the roof. Lowering the albedo of roofing materials will impose higher roof surface temperature by solar radiation and could damage the roof by enhancing chemical reactions inside the roofing materials. Also, the roof might experience higher thermal
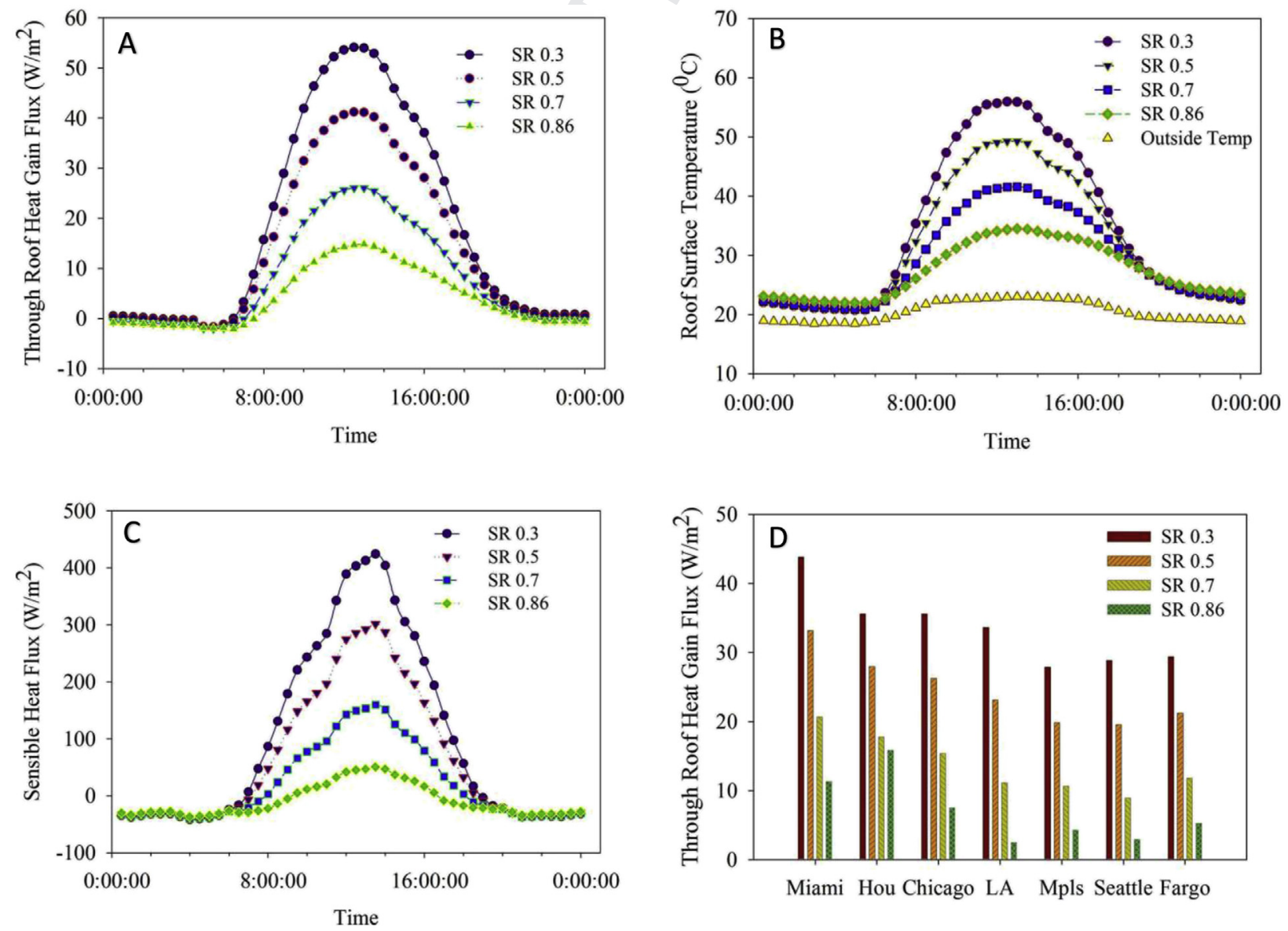

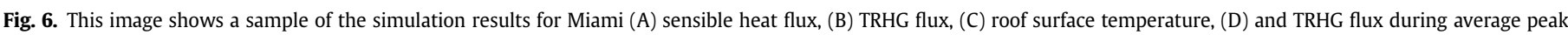
hours for seven major US cities for various solar reflectivity (albedo) values. 
stress due to uneven thermal expansion. Fig. 6B shows the daily fluctuation of roof surface temperature. For higher albedo roofing material (SR 0.86) the temperature change is $12{ }^{\circ} \mathrm{C}$, whereas for traditional lower albedo (SR 0.3) absorptive material the temperature difference is $38^{\circ} \mathrm{C}$. Therefore, roofing materials with a higher albedo will experience much less thermal fatigue.

Cool roofs are becoming very popular with the building service professionals as it maintains lower thermal stresses, lower energy cost, and higher UHI mitigation compared to any traditional radiation absorptive roof (e.g. typical gray concrete roof has SR 0.2, and asphalt roof has SR 0.05) [2,5,11]. Implementing cool roof in a new construction or during renovation could avoid any additional cost as it provides a competitive retail price. Additionally, implementing cool roof is environmentally friendly due to its prolonged lifecycle expectation.

Fig. 7 shows the simulation results of roof surface temperature and TRHG flux over a $24 \mathrm{~h}$ period for the seven major cities listed in Table 2. These plots helped to expose further subtle differences between climatic regions. During simulation, solar reflectivity values were kept constant at 0.7 for those cities to capture the effect of the different climatic zone on UHI mitigating parameter (roof surface temperature) and energy saving parameter (TRHG flux). TRHG flux was chosen over sensible heat flux since sensible heat flux is a function of roof surface temperature and related by a factor of heat transfer coefficient only. The relationship between those two properties is explained further in details in section 3.1.2. TRHG flux was also evaluated in cool roof analysis for all climatic zones as shown in Figs. 6, 8 and 9.

\subsubsection{Effects of roofing materials}

Sensible heat flux, TRHG flux and roof surface temperature, were modeled for a set of differing roof materials/type. EnergyPlus simulations were performed over the same $24 \mathrm{~h}$ time interval during the hottest week of the summer that was used previously in section 3.1.1, and repeated for the seven climatically diverse cities stated in Table 2. Fig. 8 provides a graphical sampling of this data set. This particular example was based on the climate of Houston, TX.

Table 5 shows the optical and thermal properties of different roofing materials that were used in this study. Properties were taken from the vendor database of cool roof rating council [30]. Since solar reflectivity is the key measure of cool roof classification, its value for any particular roof type was chosen approximately around $0.625 \pm 1.5$. It is also noticeable that solar reflective index, SRI (i.e., it incorporates solar reflectivity and emissivity) has almost the same magnitude of $74.5 \pm 3.5$ for different roof types. SRI values also confirm that the contribution of solar radiation is equivalent for all roofing materials. In Table 5, other relevant properties of roofing materials are listed, e.g., thermal conductivity and volumetric heat capacity (i.e., a product of specific heat and density). Thermal conductivity can be used to measure the amount of heat flow through the roofing material. And volumetric heat capacity (i.e., a product of specific heat and density) is used to calculate the amount of heat stored in the roofing materials while undergoing a given temperature change. The ratio of thermal conductivity and volumetric heat capacity is defined as thermal diffusivity and it specifies how rapidly a spatial temperature difference equalizes in a roof layer.

The simulation results shown in Fig. 8A indicate that metal roofs give the highest TRHG flux, followed by the concrete tile, and the lowest is in asphalt shingles roofs over the 24-h interval. These simulation results can be interpreted by thermal conductivity and thermal diffusivity values of different roofing materials; metal roofs shows the highest peak hours TRHG flux due to its higher thermal conductivity and diffusivity. Since both thermal conductivity and diffusivity are responsible for the heat flow through the roof from outside to building interior, higher values of those properties have detrimental effects on building energy saving. Similarly, results of other roofing materials can also be explained by thermal conductivity and diffusivity values as listed in Table 5.

Fig. $8 \mathrm{~B}$ and $\mathrm{C}$ showed the surface temperature and sensible heat flux respectively. In this instance, the results for all roofing materials matched closely. However, the metal roof showed slightly higher values in both categories compared to other roof types, while the asphalt shingle roof showed the lowest surface temperature and sensible heat flux. Similar results of sensible heat flux and roof surface temperature for different roofing materials can be explained by equivalent solar radiative properties as shown in Table 5. In Fig. 8B and C, both sensible heat flux, and roof surface temperature values show a similar behavior since both parameters only differ by a factor of heat transfer coefficient as shown in Eq. (1), provided that ambient temperatures are same in both instances. Since TMY3 weather data [28] for Houston was taken as an input for simulation, ambient temperature is same in both instances. Therefore, sensible heat flux and roof surface temperature are related by only a heat transfer coefficient parameter.

Fig. 8D describes a comparison between the various roof types across each city. Each city was in agreement that metal roof gained the most heat, followed by concrete tiles, build-up roof, the single ply membrane, and lastly the asphalt shingle. Regionally, the
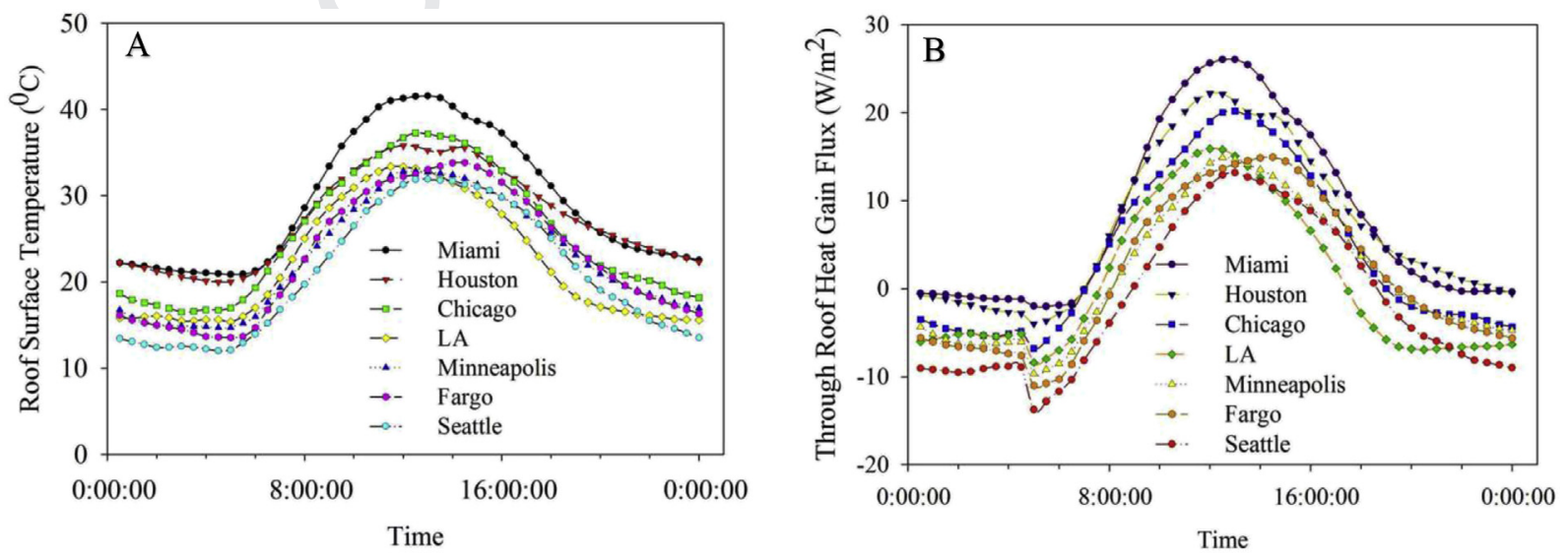

Fig. 7. Simulation results of cool roof with $S R=0.7$ for different US cities for (A) roof surface temperature, (B) TRHG flux. 

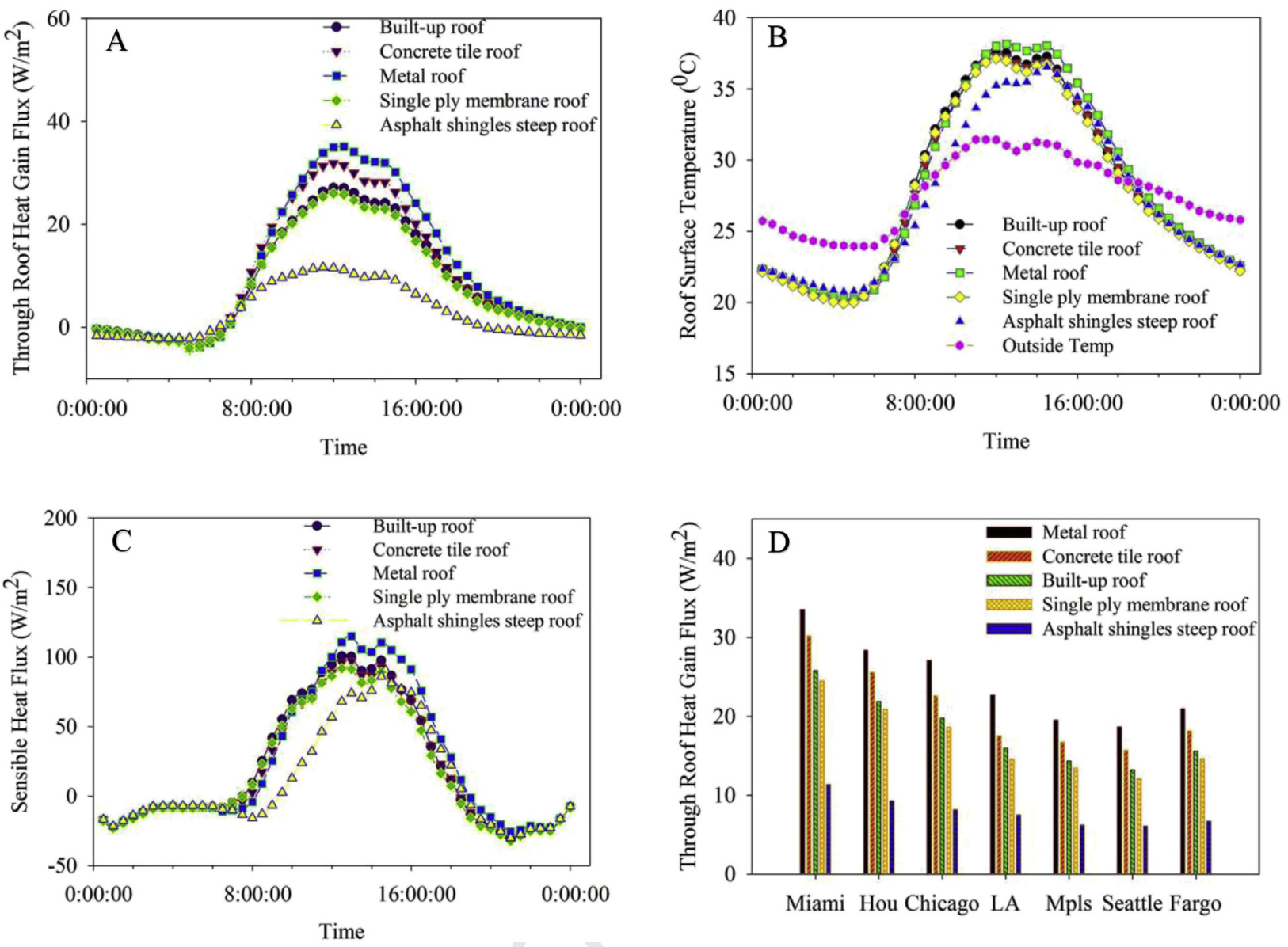

Fig. 8. This image shows a sample of the simulation results for Houston (A) sensible heat flux, (B) TRHG flux, (C) roof surface temperature, (D) and TRHG flux during average peak hours for seven major US cities for various roof materials.

highest amount of heat gained by the tested roofs was in Miami, followed by Houston, Chicago, Los Angeles, Minneapolis, Seattle, and Fargo.

\subsubsection{Effects of insulation}

The addition of insulation can significantly affect the amount of heat transfer through a roof. Fig. 9 illustrates this effect on TRHG flux, roof surface temperature and sensible heat flux for varying degrees of insulation. Fig. 9A shows that as the R-value of the insulation increases, the TRHG flux decreases. R-value is a measure of resistance to heat flow through a given thickness of the material. It is the ratio of material thickness and thermal conductivity. For the same thickness materials, R-values dictate how well these materials can resist the heat flow. However, the same is not true for surface temperature and sensible heat flux. In Fig. 9B and C, there are little difference between varying degrees of insulation. These simulation results suggest that while the addition of insulation is great for reducing the TRHG flux, potentially increasing energy savings and overall roof efficiency, it has little effect on reducing the UHI effect. Especially during peak hours in the day, lower insulation levels increase the heat flow from the exterior roof surface to the building interior, which increases the energy cost considerably. Furthermore, as higher insulation resists the heat flow through the roof, it causes slightly higher roof surface temperature than a roof with lower insulation. Also, with the increase of roof surface temperature surrounding environment will experience a small rise in sensible heat flux. Implementing higher insulation, however, reduces the energy cost significantly as it can be inferred from the peak hours TRHG flux as shown in Fig. 9A. Fig. 9D shows TRHG flux for insulation variation among different US cities. For each city, TRHG flux decreases with the increase of R-value and it shows a similar pattern for all the cities.

\section{2. $P C M$}

For any particular type of PCM, the storage system has to be sized appropriately before it is possible to implement it to a roof structure. The thickness of two commercial PCM, BioPCM@ M182Q21 and Enerciel 22, were taken from the manufacturers database. Optimum thicknesses of the remaining PCM roof types were calculated using the relationship proposed by Peippo et al. [38]. Equation (7) was used to calculate the thickness of inorganic $\left(\mathrm{CaCl}_{2} \cdot 6 \mathrm{H}_{2} \mathrm{O}\right)$, organic (Paraffin) and eutectic (Eutectic Salt) PCM roof types based on the assumption that the PCM slab needs to melt and solidify during any single day.

$t_{o p t}=\frac{t_{n} h_{r}}{\rho \mathrm{L}}\left(T_{P C M, o p t}-T_{n}\right)$

where, $T_{P C M}$ opt is the optimum phase change temperature of PCM roofing, $T_{n}$ is nighttime temperature, $t_{n}$ is PCM discharging time during night, $\rho$ is PCM density, $L$ is the PCM latent heat capacity, and $h_{r}$ is heat transfer coefficient.

Table 6 shows the optical and thermophysical properties of various PCM materials that were used for the simulation. The most important parameter impacting the effectiveness of PCM roofing is 

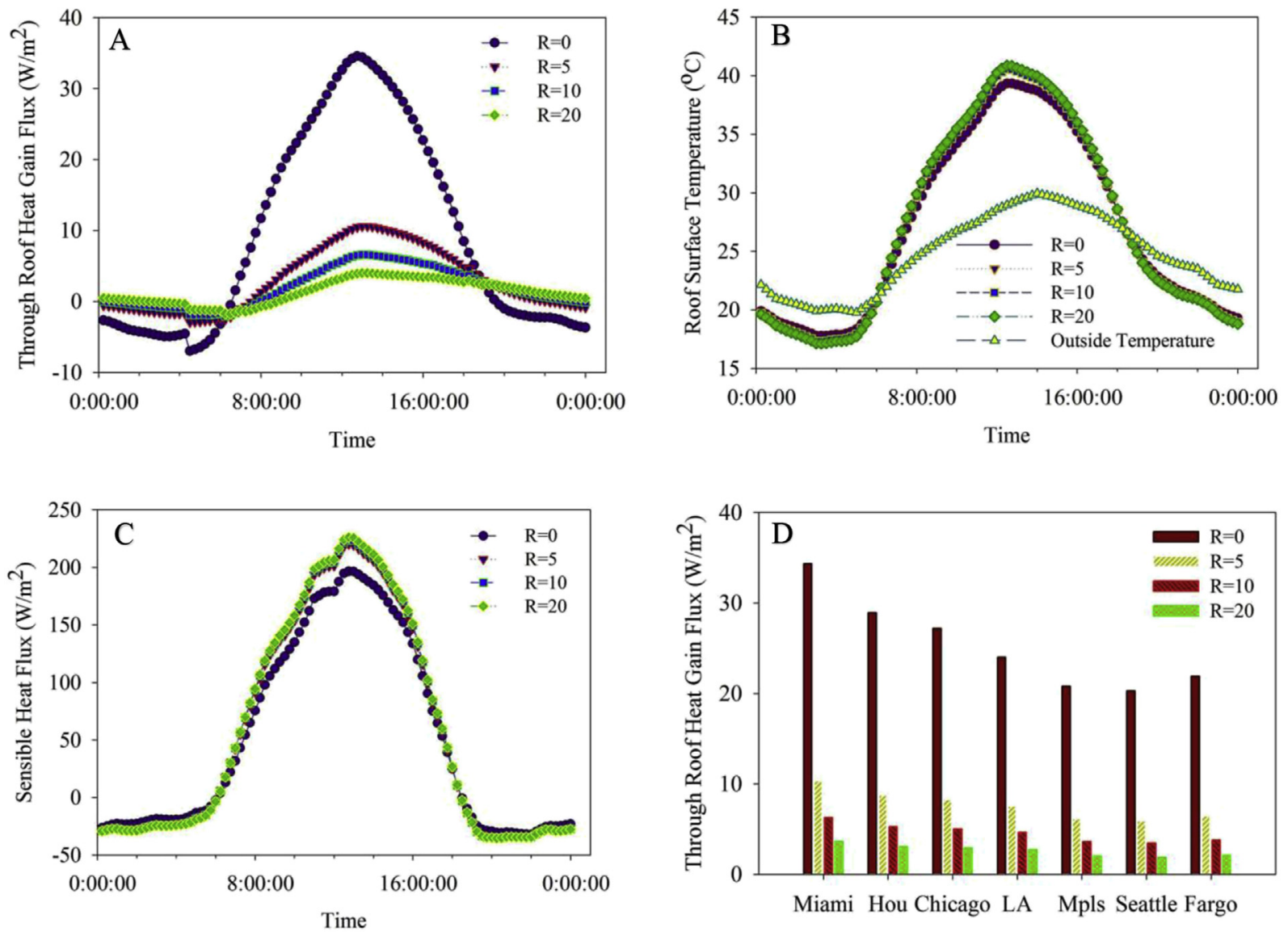

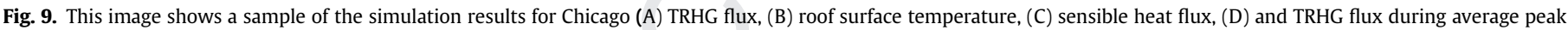
hours for seven major US cities for various thicknesses of insulation.

Table 5

Optical \& thermal properties for different roof types used for simulation.

\begin{tabular}{|c|c|c|c|c|c|c|c|c|c|}
\hline Roof type & SR & $\varepsilon^{\mathrm{b}}$ & SRI & $\boldsymbol{k} \mathrm{W} / \mathrm{m} / \mathrm{K}$ & $C \mathrm{~J} / \mathrm{Kg} / \mathrm{K}$ & $\rho \mathrm{Kg} / \mathrm{m}^{3}$ & $\boldsymbol{R}_{\boldsymbol{f}}[34]$ & Color & Vendor/Source \\
\hline Asphalt Shingles (AS) & 0.62 & $0.9^{\mathrm{b}}$ & $74.7^{\mathrm{a}}$ & 0.04 & 1260 & 1120 & 2.17 & White & [35] \\
\hline Built-up Roof (BR) & 0.62 & 0.87 & 74 & 0.16 & 1460 & 1120 & 1.67 & Bright White & [31] \\
\hline Single Ply Membrane(SPM) & 0.64 & 0.91 & 78 & 0.17 & 900 & 1390 & 1.13 & Tan & [36] \\
\hline Concrete Tile $(\mathrm{CT})$ & 0.62 & 0.88 & 74 & 1.5 & 1000 & 2100 & 1.52 & Off-White & [30] \\
\hline Metal Roof (MR) & 0.61 & 0.83 & 71 & 17 & 460 & 7900 & 1.11 & Off-White & [37] \\
\hline
\end{tabular}

Cool roof properties are taken from CRRC [30].

a SRI value was calculated by using ORNL SRI Calculator (ASTM E1980-01).

b Emissivity value was taken from DOE building benchmark model [33].

the PCM latent heat capacity, L, as the PCM uses the latent heat capacity to charge and discharge the energy. Its effectiveness depends on the melting-solidification cycle during the day. Other important properties of PCM roofing listed in Table 6 are thermal conductivity, specific heat capacity, density and optimum thickness. Thermal conductivity and volumetric heat capacity (i.e., a product of specific heat and density) dictate how effectively PCM roof allow the heat to pass through the roofing layer, and optimum thickness controls the amount of heat flow for any particular PCM configuration.

A plot of the specific enthalpy (the sum of specific internal energy and pressure times specific volume) at various temperatures is

Table 6

Optical \& thermophysical properties for various PCM materials installed in DOE benchmark built-up roof.

\begin{tabular}{|c|c|c|c|c|c|c|c|c|}
\hline PCM material & Optical properties & $\mathrm{K} \mathrm{W} / \mathrm{m} / \mathrm{K}$ & $\mathrm{C} \mathrm{J} / \mathrm{kg} / \mathrm{K}$ & $\rho \mathrm{kg} / \mathrm{m}^{3}$ & $\mathrm{~L} \mathrm{~kJ} / \mathrm{kg}$ & $\mathrm{t}_{\mathrm{opt}} \mathrm{cm}$ & Phase change temperature $\left({ }^{\circ} \mathrm{C}\right)$ & Vendor/Source \\
\hline BioPCM@M182Q21 & $\varepsilon=0.9, \mathrm{SR}=0.9, \mathrm{SRI}=114.4$ & 0.2 & 1970 & 235 & 196 & 7.4 & $21-24$ & [39] \\
\hline Enerciel 22 & & 0.148 & 7085 & 832 & 177 & 0.3 & $18-29$ & [40] \\
\hline Eutectic Salt $^{\mathrm{a}}$ & & 0.54 & 1440 & 1640 & 188 & 0.63 & $26-28$ & [41] \\
\hline Paraffin $\left(\mathrm{C}_{16}-\mathrm{C}_{18}\right)$ & & $0.148[42]$ & 534 & 775 & 152 & 0.33 & $21-24$ & [43] \\
\hline $\mathrm{CaCl}_{2} \cdot 6 \mathrm{H}_{2} \mathrm{O}$ & & $0.6[44]$ & 1450 & 1050 & 160 & 1.62 & $28.5-30.2$ & [45] \\
\hline
\end{tabular}

a Eutectic Salt $=48 \% \mathrm{CaCl}_{2}+4.3 \% \mathrm{NaCl}+0.4 \% \mathrm{KCl}+47.3 \% \mathrm{H}_{2} \mathrm{O}$. 


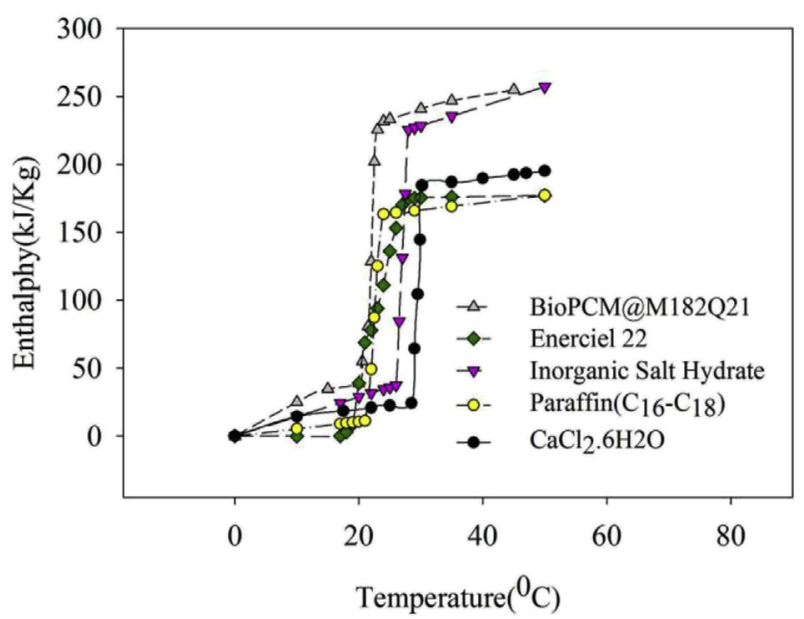

Fig. 10. Enthalpy variation for different PCM with temperature.

shown in Fig. 10 for the various types of PCM materials evaluated. Here, the enthalpy illustrates a graphical representation of the phase change. Although there is a definite increase in enthalpy, the temperature remains relatively constant around $22{ }^{\circ} \mathrm{C}$. The BioPCM@M182Q21 shows the most dramatic change in enthalpy of the materials, indicating the greatest capacity to store latent heat across a phase change.
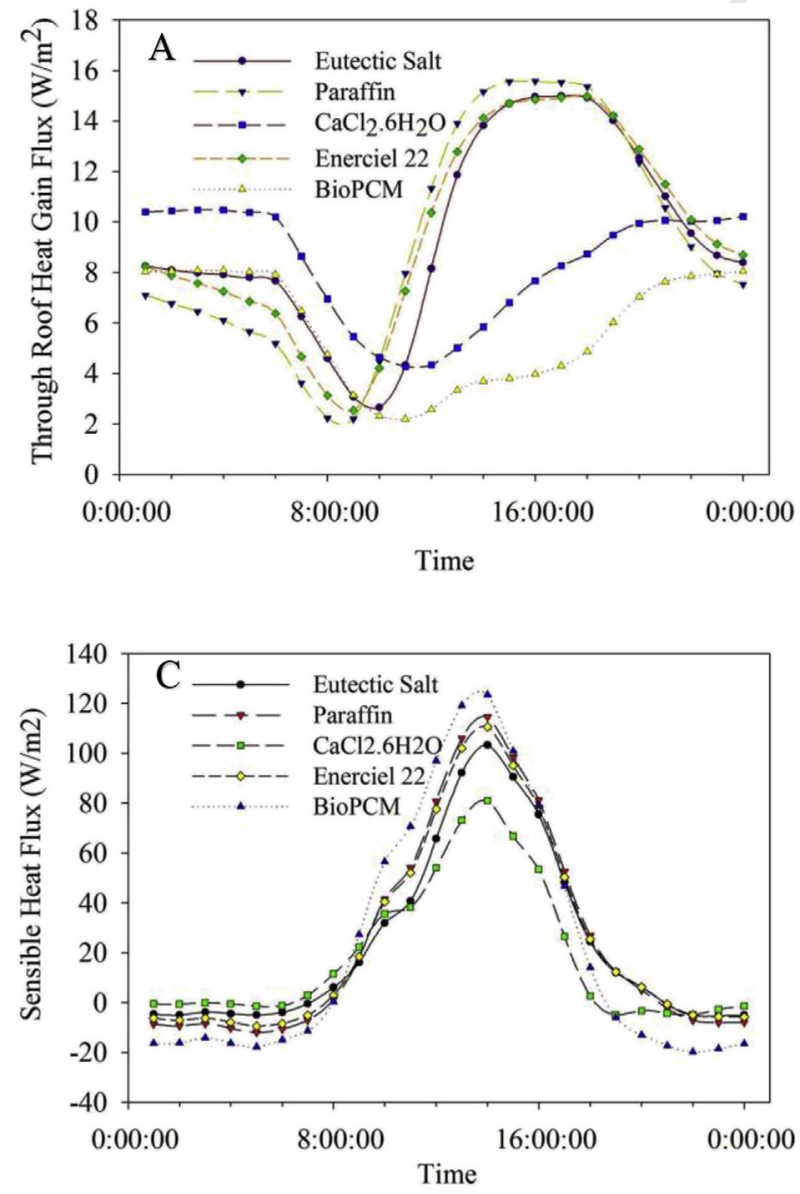

\subsubsection{Effects of different PCM as a roof internal layer}

Different types of PCM were added as an internal roof layer, evaluated for the representative week and averaged over a $24 \mathrm{~h}$ interval. Again, the TRHG flux, surface temperature, and sensible heat flux were all considered. Fig. 11A specifically shows the TRHG flux effects of PCM materials within the envelope of the roof. Here, there is a significant difference between the BioPCM, $\mathrm{CaCl}_{2} \cdot 6 \mathrm{H}_{2} \mathrm{O}$ and the other PCM materials. BioPCM and $\mathrm{CaCl}_{2} \cdot 6 \mathrm{H}_{2} \mathrm{O}$ average TRHG flux during peak hours were $3.25 \mathrm{~W} / \mathrm{m}^{2}$ and $8.51 \mathrm{~W} /$ $\mathrm{m}^{2}$ respectively, while all other PCM types were closer to $15 \mathrm{~W} / \mathrm{m}^{2}$. This indicates that the use of BioPCM and $\mathrm{CaCl}_{2} \cdot 6 \mathrm{H}_{2} \mathrm{O}$ PCM types within the envelope of a roof could reduce the amount of energy consumption. The surface temperature and sensible heat flux shown in Fig. 11B and $\mathrm{C}$ reveal more agreement between the PCM types. BioPCM yields a maximum sensible heat flux value of $123.4 \mathrm{~W} / \mathrm{m}^{2}$. Fig. 11D illustrates the TRHG flux across the seven representative cities. From this plot, it is clear that the Paraffin and Enerciel-22 yield the largest TRHG flux across the country. These results collectively indicate that both BioPCM and $\mathrm{CaCl}_{2} \cdot 6 \mathrm{H}_{2} \mathrm{O} \mathrm{PCM}$ will serve to mitigate UHI by reducing energy demands through a reduction in TRHG flux, and $\mathrm{CaCl}_{2} \cdot 6 \mathrm{H}_{2} \mathrm{O}$ PCM also seems to contribute to UHI mitigation through reduced surface temperature and sensible heat flux.

Although the simulation results indicate paraffin generates a large TRHG flux, surface temperature, and sensible heat flux, it remains one of the more popular PCM material types used [46]. Paraffin has favorable properties as a building envelope material
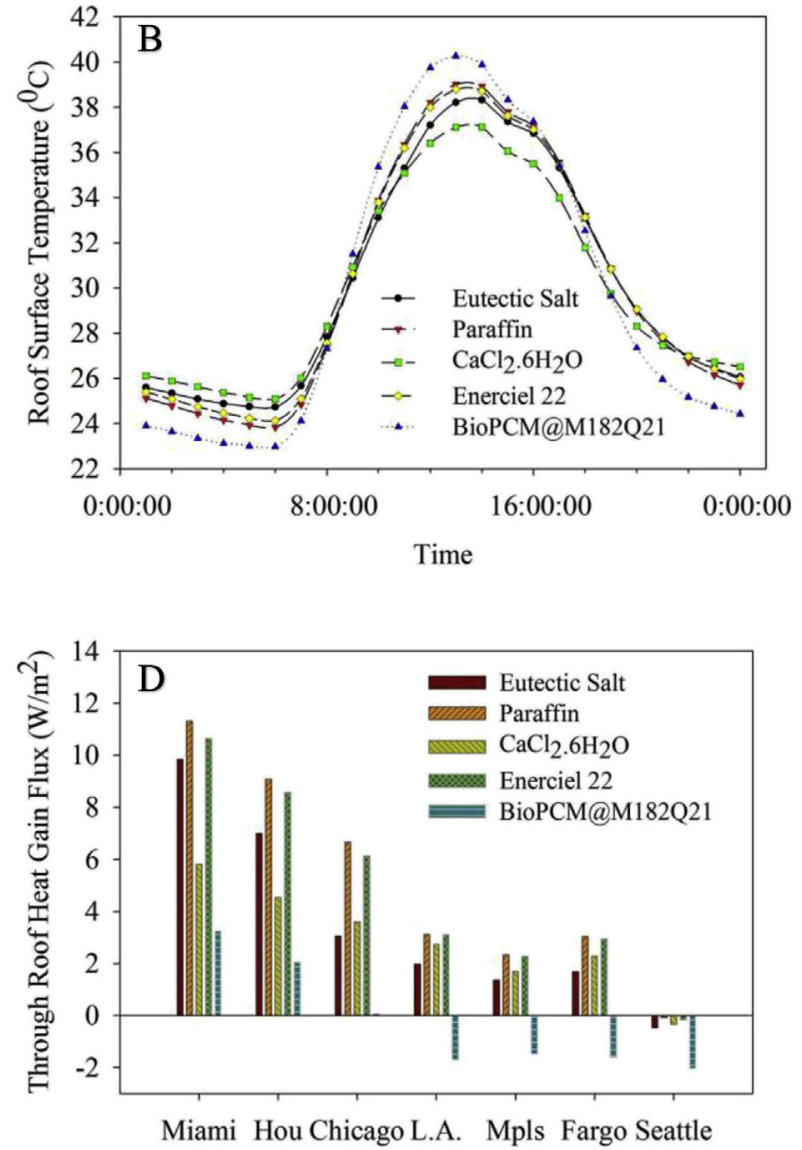

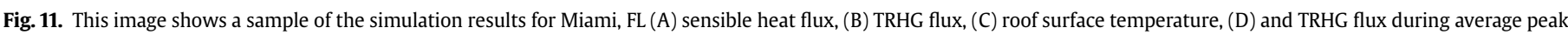
hours for seven major US cities for various PCM slab as a roof internal layer. 

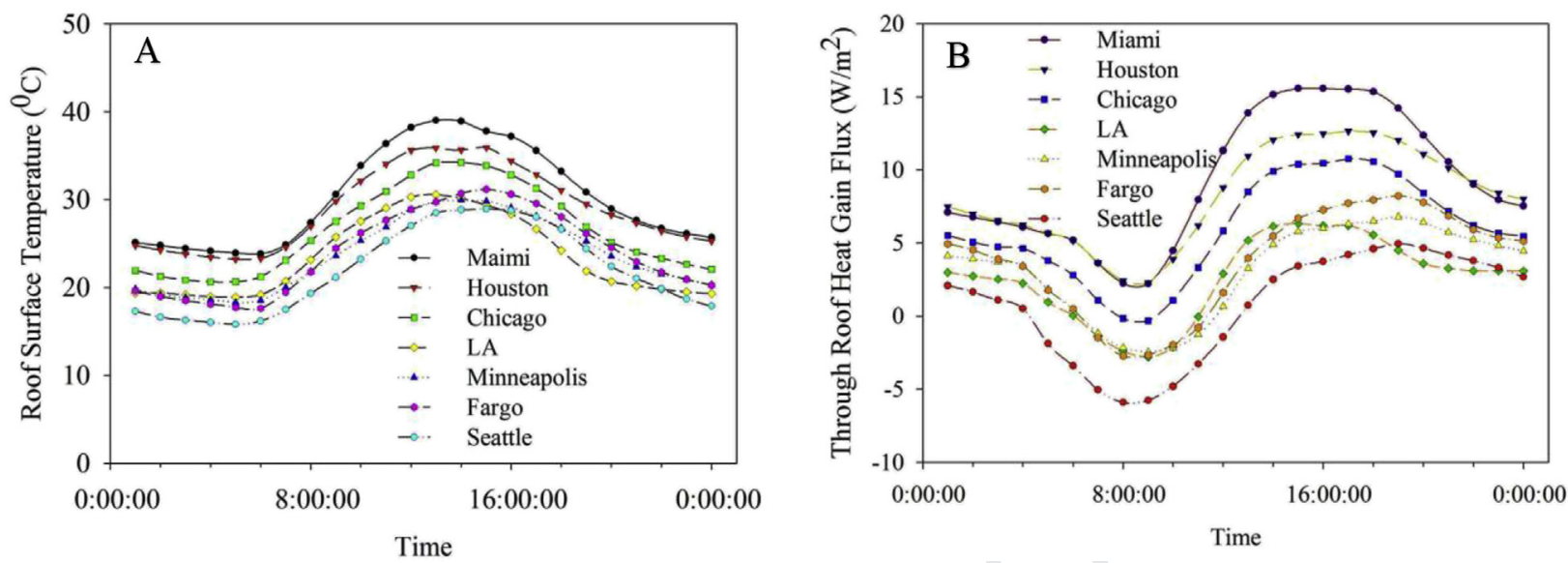

Fig. 12. Simulation results of Paraffin PCM layer in roof for different US cities for (A) roof surface temperature, (B) TRHG flux.

over other types, e.g., chemically stable, strong resistance to supercoiling, non-corrosive, non-toxic, and high latent heat of fusion [18]. Also, paraffins are available in a broad range of melting temperatures, they are chemically inert, have low vapor pressure, and shows no indication of thermal performance degradation by thermal cycling. Thus, Paraffin was used for the rest of PCM analysis. Fig. 12 describes the effect of Paraffin within the roof envelope on the roof surface temperature and TRHG flux for each city is displayed over a $24 \mathrm{~h}$ period. Roof surface heat gain were chosen over sensible heat flux to compare the effect of heat flux on different US cities since it was selected before to analyze the peak hours TRHG flux as shown in Fig. 11. These plots provide another vantage point with which to elucidate any subtle differences between climatic regions.

\subsubsection{Effects of roof type with paraffin PCM slab as a roof internal} layer

Various roof types combined with a slab of paraffin PCM inserted within the envelope of each roof were modeled and compared with one another over $24 \mathrm{~h}$ during the hottest week of the summer.
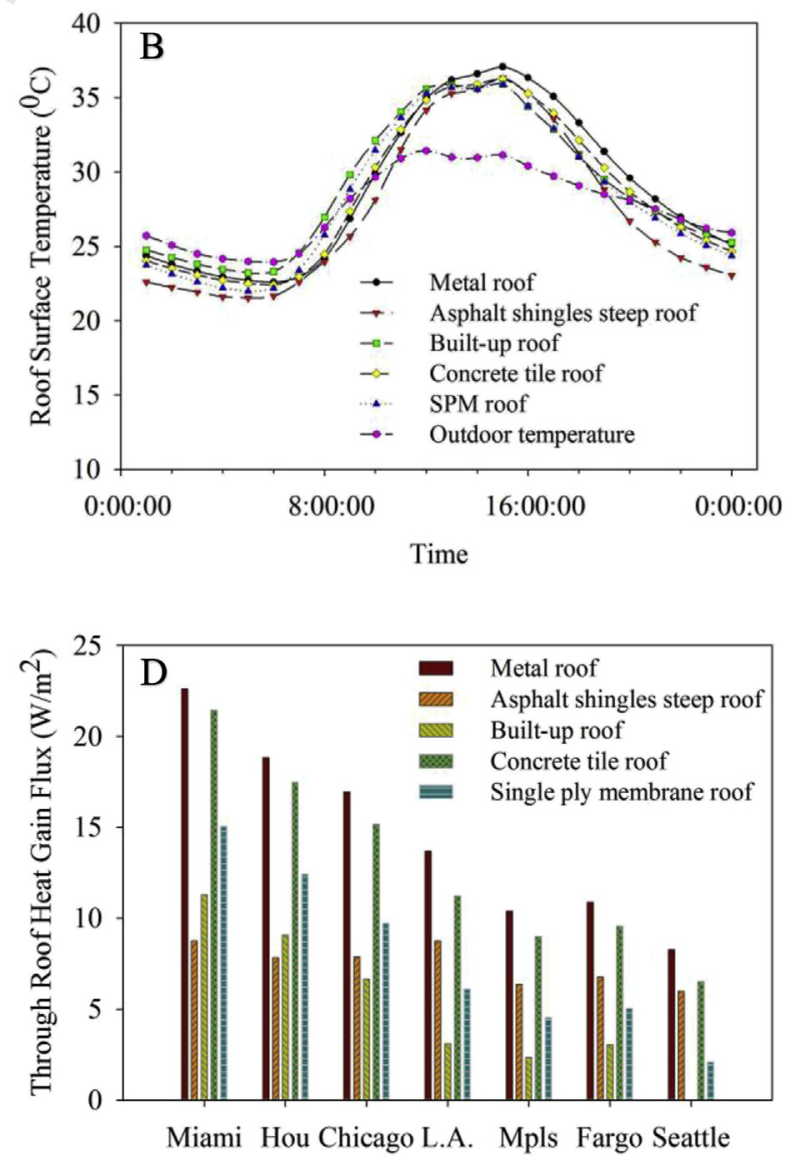

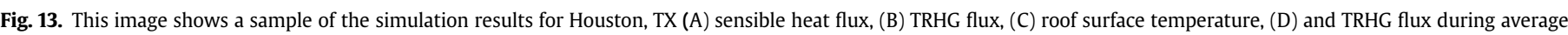
peak hours for seven major US cities for various roof type with a paraffin PCM slab as a roof internal layer. 
Again, TRHG flux, roof surface temperature, and sensible heat flux were considered, as well as the TRHG flux across climatic regions across the country. Fig. 13 shows the simulation results. TRHG flux is displayed in Fig. 13A. This plot clearly shows how well the asphalt shingle roof in combination with the paraffin reduces TRHG flux during peak hours. The built-up roof type was also notable in reducing the TRHG flux. The maximum TRHG flux for the asphalt and built-up roof types were $9.98 \mathrm{~W} / \mathrm{m}^{2}$ and $12.65 \mathrm{~W} / \mathrm{m}^{2}$ respectively. Unlike for cool roof where conduction plays a major role in TRHG flux values, in PCM roofing it's a rather complicated phenomenon which has contribution from conduction, convection, complex shapes of the phase change boundary and volume changes. According to our previous discussion in section 3.1.2 it can be deduced that metal roofs contribute the highest TRHG flux due to its superior thermal conductivity and diffusivity properties. The minimum TRHG flux is by asphalt shingle roofs due to its lowest thermal conductivity and diffusivity values. Since Paraffin was used as a PCM material for all different types of roofing materials, the simulation results for TRHG flux shows a similar pattern like cool roof results as shown in section 3.1.2.

Fig. 13B and C indicate little difference between each roof type for both the roof surface temperature and sensible heat flux. This phenomenon can be explained by similar optical properties for any particular roof type by keeping SR at $0.625 \pm 1.5$ and SRI at $74.5 \pm$ 3.5. Paraffin PCM has an almost negligible influence on either of those two parameters, roof surface temperature and sensible heat flux values.

Lastly, Fig. 13D illustrates the TRHG flux across each climatic region within the United States. Here, metal and concrete tile roof
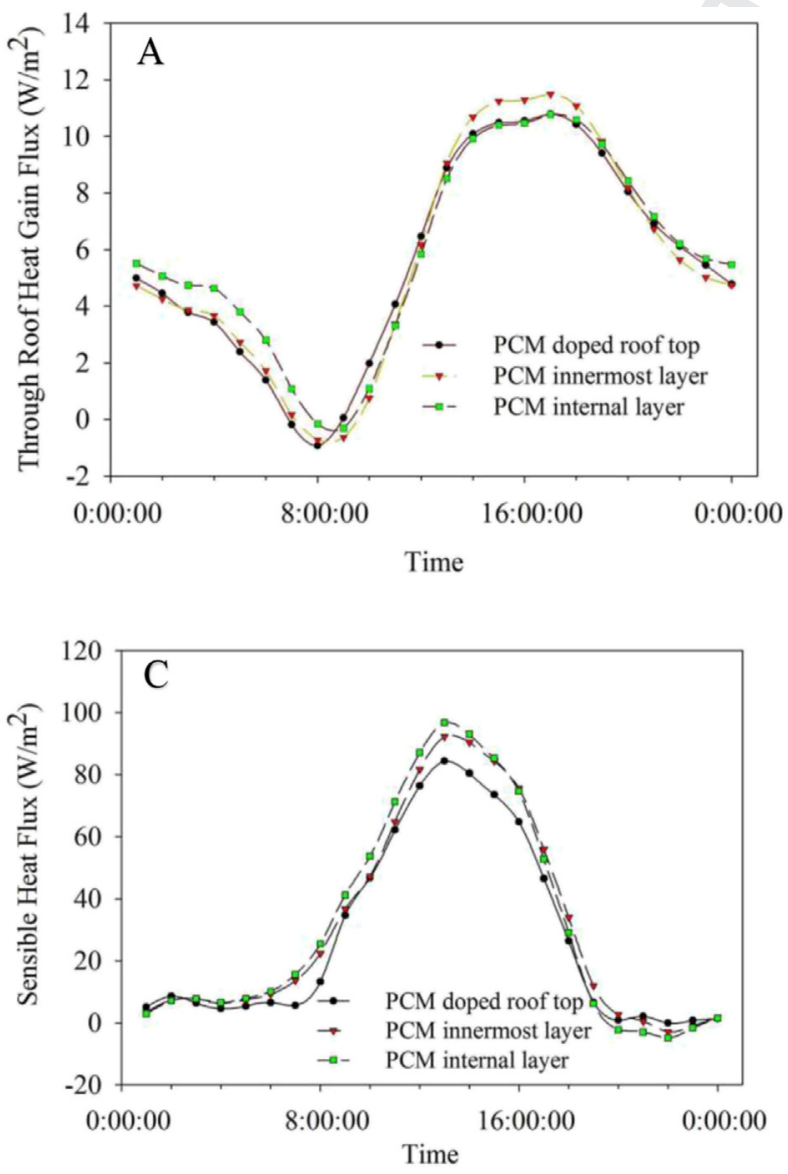

types with paraffin PCM within the envelope of the roof illustrate the highest TRHG flux in each region, while the built-up roof and single ply membrane roof consistently show less TRHG flux than the metal and concrete tile roofs. The Asphalt roof has low values of peak TRHG flux, with small variation between the different regions. The combination of asphalt roof with a PCM layer would be an excellent choice for any region to reduce UHI effects. Depending on the location, the built-up roof or single ply membrane roofs, each with a PCM layer, could provide the best mitigation against UHI.

\subsubsection{Effects of PCM slab location in roof}

The effects of PCM at various depths within the envelope of the roof were evaluated. Fig. 14 contains the TRHG flux, roof surface temperature, and sensible heat flux for each depth (roof top, the innermost layer, and the middle layer). Fig. 14(A-C) all indicate little difference between any of the PCM locations. It is noticeable that when PCM placed as an innermost layer inside the roof it shows a slight increase of TRHG flux on peak hours during the day. Placing the PCM as an innermost layer could lead to higher energy expenditure by increasing the cooling load demand during peak hours. Simulation results displayed in Fig. 14D illustrate that this trend between PCM locations within the envelope is the same through the country. However, there are still clear differences in the TRHG flux across the different regions. It can be concluded that the location of a PCM layer within a roof envelope is not an important factor when considering UHI mitigation strategies. Other factors, such as air or water tightness, should be given priority over PCM depth.
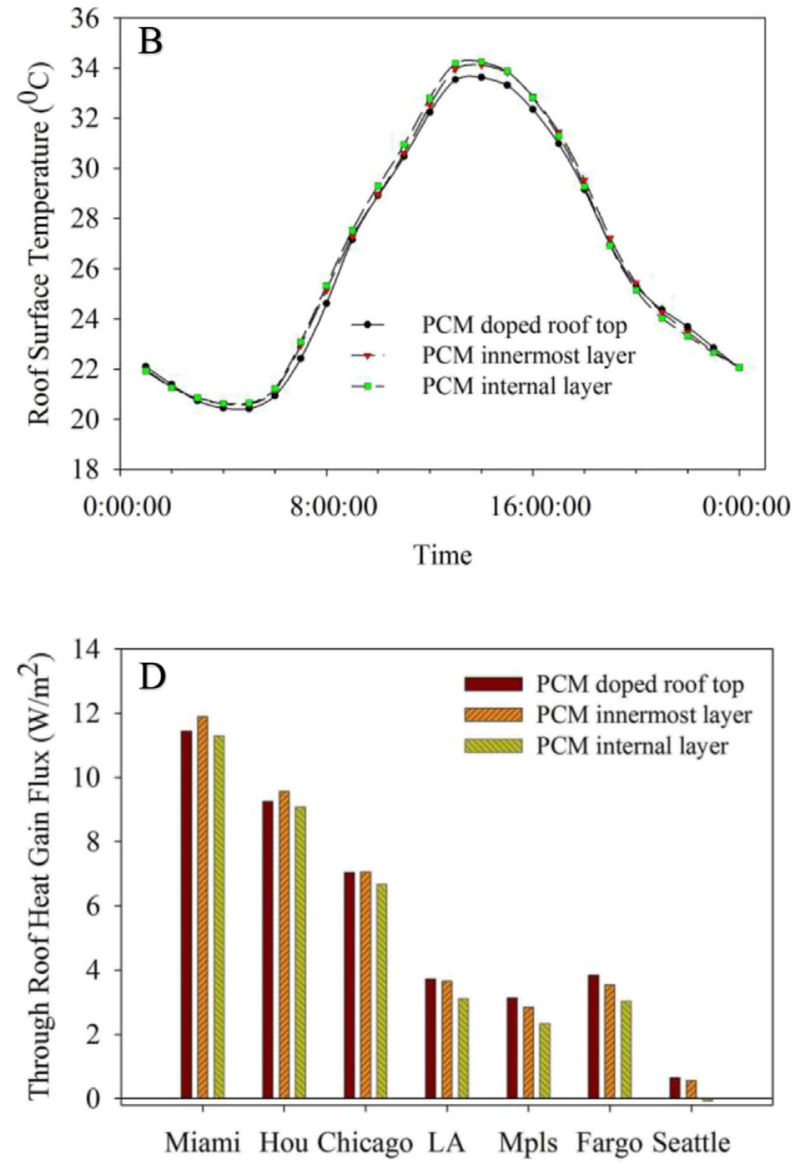

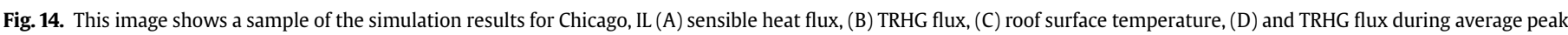
hours for seven major US cities for various roof type with a PCM slab as a roof internal layer. 

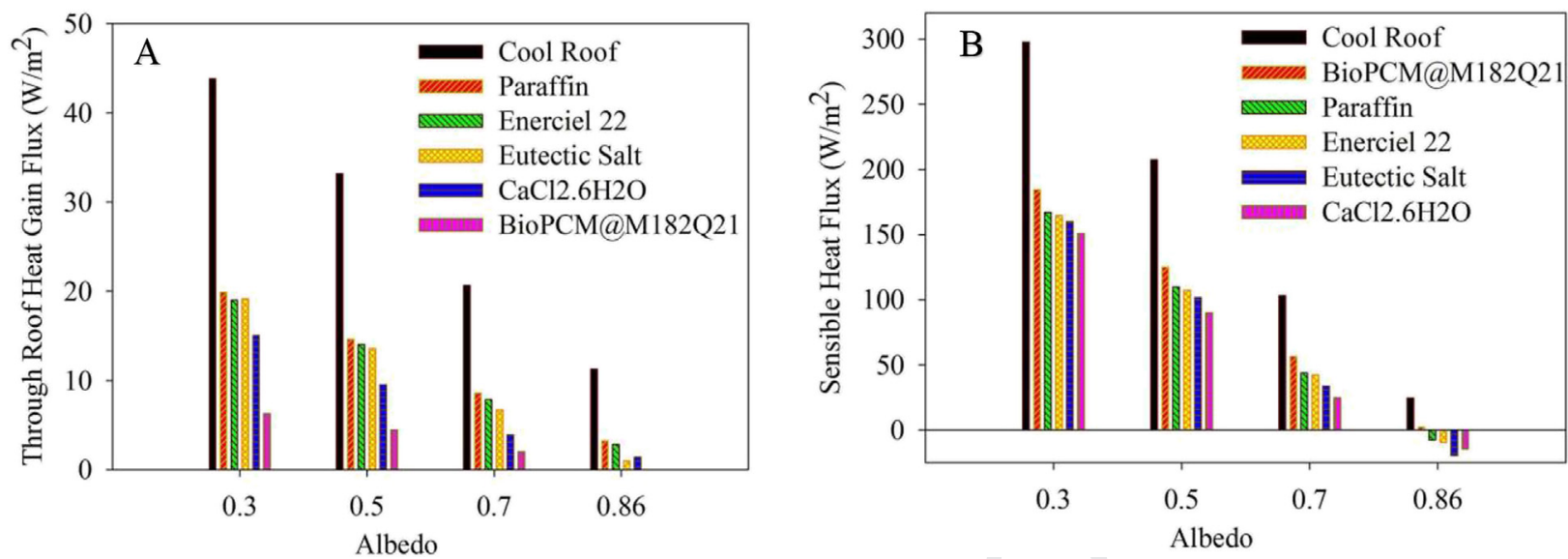

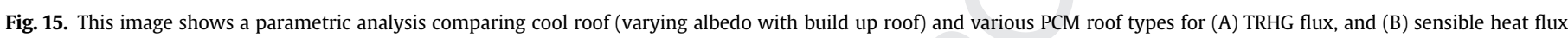
across a range albedo values in Miami, FL.

\subsection{Parametric analysis}

The peak hours TRHG flux and sensible heat flux for various cool roofs and PCM roofs are analyzed in a comparative manner for all major US cities. In section 3.1.3 and 3.2.3 it was shown that insulation thickness variation and PCM slab location has negligible UHI contribution. For parametric analysis of cool roofs and PCM roofs, the main parameters chosen for potential UHI mitigation were albedo, roofing materials, and PCM types. This selection of primary UHI influencing parameters was based on the results of section 3.1.1, 3.1.2, 3.2.1, and 3.2.2.

\subsubsection{Effects of albedo on PCM variation}

A parametric analysis was performed to compare the sensible heat flux and TRHG flux computed from simulation results for cool roof with different albedo or solar reflectivity values and various PCM roof types. Fig. 15 clearly shows the significant differences between cool roof and PCM. The TRHG flux during peak hours for a variety of albedo values are displayed in Fig. 15A. The bar chart shows that cool roof technology yields a TRHG flux nearly twice as large as any of the PCM roof types. Since TRHG flux is directly related to energy saving measures, it could bring a huge relief to the building owners by reducing the energy bill. However to predict the economic benefit precisely for using the PCM roofs over cool roof, a detail comprehensive analysis will be needed. The same trend occurs in Fig. 15B, where sensible heat flux values for cool roof technology are again found to be much larger than the competitive PCM roof types. Conclusively, this information illustrates the use of PCM within the envelope of a roof could potentially improve energy savings, and reduce UHI effects much more efficiently than cool roof technology. The PCM type that yielded the lowest TRHG flux during peak hours of a warm week of the summer was the BioPCM. The maximum TRHG flux was $6.32 \mathrm{~W} / \mathrm{m}^{2}$ at the low albedo value of 0.3 . $\mathrm{CaC}_{2} \cdot 6 \mathrm{H} 2 \mathrm{O}$ generated the least amount of sensible heat flux with a maximum of $150.9 \mathrm{~W} / \mathrm{m}^{2}$ at an albedo value of 0.3 .

\subsubsection{Effects of albedo on roofing materials}

Another analysis comparing the effects of albedo on various roofing materials was performed. Fig. 16 illustrates the TRHG flux and sensible heat flux during peak hours for various albedo values. Both Fig. 16A and B indicate that the asphalt shingle roof type provided lower TRHG flux and sensible heat flux values across the range of albedo values. Thus, the use of an asphalt shingle roofs could provide an increase energy savings and a reduction in UHI effect. The maximum TRHG flux and sensible heat flux values for the asphalt roof type were $14.53 \mathrm{~W} / \mathrm{m}^{2}$ and $152.4 \mathrm{~W} / \mathrm{m}^{2}$ respectively. Fig. 16A shows that the differences between maximum and minimum peak hours TRHG flux for different roofing materials have much higher values for lower albedo roofing materials. It indicates that with the increase of roof surface albedo, the building
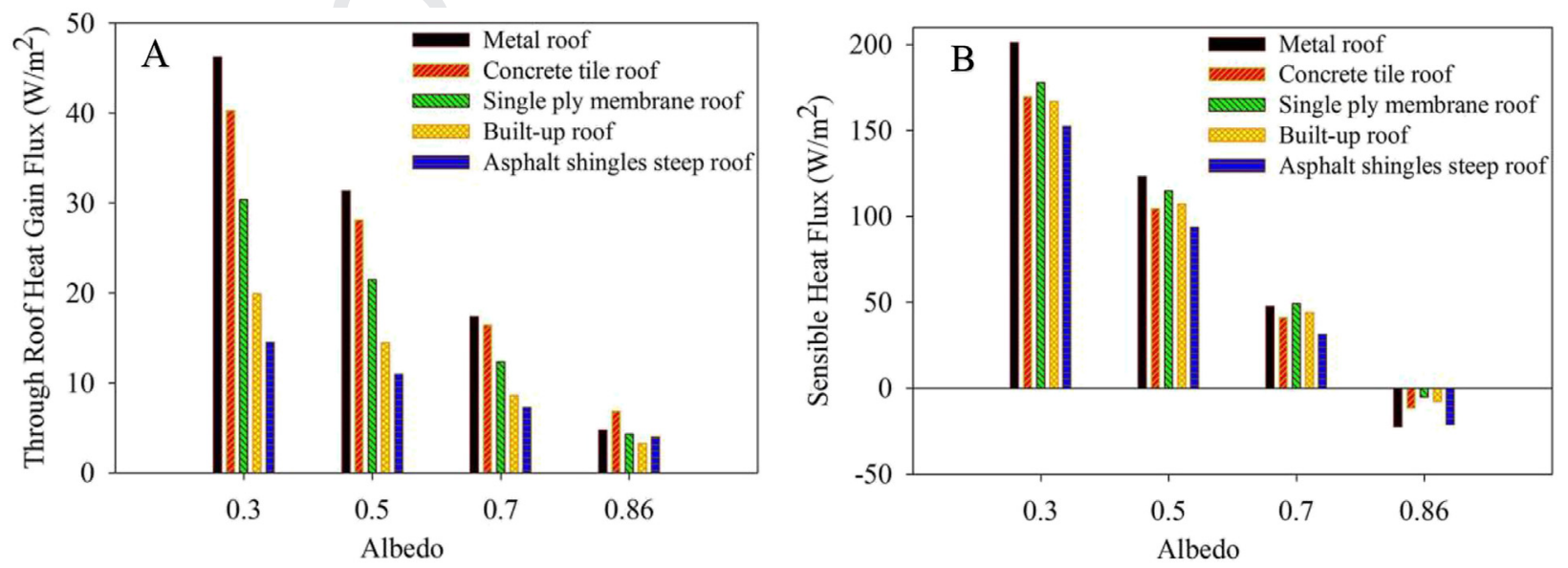

Fig. 16. This image shows a parametric analysis comparing various roof materials for (A) TRHG flux, and (B) sensible heat flux across a range of albedo values for Miami, FL. 
will have much greater potential for lowering the energy cost for almost any types of building roofing materials. In particular, peak hours TRHG flux differences for different roof materials with albedo of $0.86,0.7,0.5$, and 0.3 are $2.84 \mathrm{~W} / \mathrm{m}^{2}, 10.1 \mathrm{~W} / \mathrm{m}^{2}, 20.4 \mathrm{~W} / \mathrm{m}^{2}$, and $31.7 \mathrm{~W} / \mathrm{m}^{2}$ respectively. In Fig $16 \mathrm{~B}$ peak hours sensible heat flux differences for different roofing materials also show similar results; the differences of sensible heat flux are reduced with the increase of roof surface albedo. Peak hours sensible heat flux differences for different roof materials with albedo of $0.86,0.7,0.5$, and 0.3 are $14.6 \mathrm{~W} / \mathrm{m}^{2}, 17.9 \mathrm{~W} / \mathrm{m}^{2}, 29.5 \mathrm{~W} / \mathrm{m}^{2}$, and $48.7 \mathrm{~W} / \mathrm{m}^{2}$ respectively. It can be inferred from these findings that the increase of albedo in roofing materials have a smaller contribution to UHI mitigation.

\section{Conclusions}

Advancement in material technology for cool roof has been a continued effort throughout the world for mitigating the UHI effects. In addition to the surface properties, the materials enclosed within the roofs of buildings also play a large role towards mitigating UHI. PCM has been studied within the roof envelope along with the cool roof to help reduce energy consumption. Cool roof and PCM roof serve to improve UHI and energy performance by increasing the roof surface albedo and by storing latent heat of the roof materials respectively.

In this work a comparison of the two technologies was conducted. Cool roof materials and PCM were compared using performance parameters of roof surface temperature, thermal energy entering the enclosure via the roof, and sensible heat flux. Simulations were conducted over a range of climate zones across the United States. Multiple roof types and multiple PCM types were evaluated, and a parametric analysis was performed for the effects of albedo on PCM variations and roofing materials.

In general, with respect to reducing UHI effect, increasing albedo led to better performance. This study concluded that asphalt roofs tend to give the best results of all the roof types. Additionally, it was found that insulation did not play a significant role in the reduction of UHI effects. Ultimately, the PCM roof type proved its superiority to the cool roof technology with a maximum TRHG flux (i.e. heat flux to building interior through the roof) of $54 \%$ lower than the cool roof for various albedo. Similarly, the PCM roof technology showed a maximum sensible heat flux (i.e. heat flux from roof surface to the surrounding environment) of $40 \%$ lower than the cool roof technology for various albedo. Thus, it is clear that PCM roof technology is the future of energy-saving and heat island reducing rooftops.

\section{Acknowledgments}

The authors express their gratitude to the reviewers for their thoughtful feedback, which was used to improve the quality of the paper.

\section{References}

[1] World Urbanization Prospects, The 2014 Revision, United Nations, 2014. [Online]. Available: http://esa.un.org/unpd/wup/Highlights/WUP2014Highlights.pdf.

[2] Boixo S, Diaz-Vicente M, Colmenar A, Castro MA. Potential energy savings from cool roofs in Spain and Andalusia. Energy Feb. 2012;38(1):425-38.

[3] Zhang ZL, Yu HY, Hu ZY, Zhou B, Han MC. Urban heat island effect analysis around Hangzhou Bay between 2005 and 2009 using remotely sensed data. Appl Mech Mater Dec. 2011;143-144:639-43.

[4] Crutzen P. New directions: the growing urban heat and pollution island effect impact on chemistry and climate. Atmos Environ Jul. 2004;38(21):3539-40.

[5] Akbari H, Konopacki S, Pomerantz M. Cooling energy savings potential of reflective roofs for residential and commercial buildings in the United States. Energy May 1999;24(5):391-407.
[6] Gallo KP, McNab AL, Karl TR, Brown JF, Hood JJ, Tarpley JD. The use of a vegetation index for assessment of the urban heat island effect. Int J Remote Sens 1993;14(11):2223-30.

[7] Hirano Y, Fujita T. Evaluation of the impact of the urban heat island on residential and commercial energy consumption in Tokyo. Energy Jan. 2012;37(1):371-83.

[8] Kolokotsa D, Santamouris M, Zerefos SC. Green and cool roofs' urban heat island mitigation potential in European climates for office buildings under free floating conditions. Sol Energy Sep. 2013;95:118-30.

[9] Santamouris M. Cooling the cities - a review of reflective and green roof mitigation technologies to fight heat island and improve comfort in urban environments. Sol Energy May 2014;103:682-703.

[10] Li D, Bou-Zeid E, Oppenheimer M. The effectiveness of cool and green roofs as urban heat island mitigation strategies. Environ Res Lett May 2014;9(5): 055002.

[11] Akbari H, Matthews HD. Global cooling updates: reflective roofs and pavements. Energy Build Dec. 2012;55:2-6.

[12] Mastrapostoli E, Karlessi T, Pantazaras A, Kolokotsa D, Gobakis K, Santamouris M. On the cooling potential of cool roofs in cold climates: use of cool fluorocarbon coatings to enhance the optical properties and the energy performance of industrial buildings. Energy Build Feb. 2014;69:417-25.

[13] Georgakis C, Zoras S, Santamouris M. Studying the effect of 'cool' coatings in street urban canyons and its potential as a heat island mitigation technique. Sustain Cities Soc Oct. 2014;13:20-31.

[14] Karlessi T, Santamouris M, Apostolakis K, Synnefa A, Livada I. Development and testing of thermochromic coatings for buildings and urban structures. Sol Energy Apr. 2009;83(4):538-51.

[15] Chou H-M, Chen C-R, Nguyen V-L. A new design of metal-sheet cool roof using PCM. Energy Build Feb. 2013;57:42-50.

16] Barozzi GS, Corticelli MA, Libbra A, Muscio A, Tartarini P. Building structures with high thermal inertia based on phase change materials. Int J Heat Technol 2009;27(2):121-6.

[17] Kong X, Lu S, Li Y, Huang J, Liu S. Numerical study on the thermal performance of building wall and roof incorporating phase change material panel for passive cooling application. Energy Build Oct. 2014;81:404-15.

[18] Baetens R, Jelle BP, Gustavsen A. Phase change materials for building applications: a state-of-the-art review. Energy Build Sep. 2010;42(9):1361-8.

[19] Osterman E, Tyagi VV, Butala V, Rahim NA, Stritih U. Review of PCM based cooling technologies for buildings. Energy Build Jun. 2012;49:37-49.

[20] Zhang Y, Zhou G, Lin K, Zhang Q, Di H. Application of latent heat thermal energy storage in buildings: state-of-the-art and outlook. Build Environ Jun. 2007;42(6):2197-209.

[21] Arnfield AJ. Two decades of urban climate research: a review of turbulence, exchanges of energy and water, and the urban heat island. Int J Climatol Jan. 2003;23(1):1-26.

[22] Kleerekoper L, van Esch M, Salcedo TB. How to make a city climate-proof, addressing the urban heat island effect. Resour Conserv Recycl Jul. 2012;64 30-8.

[23] Kashem SB, Irawan A, Wilson B. Evaluating the dynamic impacts of urban form on transportation and environmental outcomes in US cities. Int J Environ Sci Technol May 2014;11(8):2233-44.

24] U.S. Department of Energy Commerical Reference Buildings.

[25] Baechler MC. High-performance home technologies: guide to determining climate regions by County. 2010.

[26] Clear RD, Gartland L, Winkelmann FC. An empirical correlation for the outside convective air-film coefficient for horizontal roofs. Energy Build Sep. 2003;35(8):797-811.

27] Defraeye T, Blocken B, Carmeliet J. Convective heat transfer coefficients for exterior building surfaces: existing correlations and CFD modelling. Energy Convers Manag Jan. 2011;52(1):512-22.

[28] National Solar Radiation Data Base. 2008. [Online]. Available: http://rredc.nrel. gov/solar/old data/nsrdb/1991-2005/tmy3/.

[29] DOE building benchmark model. [Online]. Available: www.energycodes.gov.

[30] Cool Roof Rating Council. [Online]. Available: www.coolroofs.org.

[31] Siplast, Inc. [Online]. Available: http://www.siplast.com/.

[32] US PLY INC. [Online]. Available: www.usply.com.

[33] DOE building benchmark model. [Online]. Available: http://energy.gov/eere/ buildings/commercial-reference-buildings.

[34] EnergyPlus Energy Simulation Software. EnergyPlus 8.0. 2014 [Online]. Available, http://apps1.eere.energy.gov/buildings/energyplus [accessed: 26.02.15].

[35] Levinson R, Akbari H, Berdahl P, Wood K, Skilton W, Petersheim J. A nove technique for the production of cool colored concrete tile and asphalt shingle roofing products. Sol Energy Mater Sol Cells Jun. 2010;94(6):946-54.

[36] Sika Corporation U.S. [Online]. Available: http://usa.sika.com/.

[37] Akzo Nobel Coatings, Inc. [Online]. Available: www.akzonobel.com.

[38] Peippo K, Kauranen P, Lund PD. A multicomponent PCM wall optimized for passive solar heating. Energy Build Jan. 1991;17(4):259-70.

[39] BioPCM, BioPCMat \& ThermaStix. [Online]. Available: http://www phasechange.com/index.php/en/about/biopcm-biopcmat-thermastix. [accessed: 29.12.14].

[40] Winco ENERCIEL. Our technology has never been so comfortable. [Online] Available: http://www.enerciel-pcm.fr/index.php? $\ln =\mathrm{en}$. [accessed: 29.12.14].

[41] Pasupathy A, Athanasius L, Velraj R, Seeniraj RV. Experimental investigation and numerical simulation analysis on the thermal performance of a building 
roof incorporating phase change material (PCM) for thermal management. Appl Therm Eng Apr. 2008;28(5-6):556-65.

[42] Ukrainczyk N, Kurajica S, Šipušiæ J. Thermophysical comparison of five commercial paraffin waxes as latent heat storage materials. Chem Biochem Eng Q 2010;24(2):129-37.

[43] Zalba B, Marın JM, Cabeza LF, Mehling H. Free-cooling of buildings with phase change materials. Int J Refrig Dec. 2004;27(8):839-49.
[44] Zaytsev ID, Aseyev GG. Properties of aqueous solutions of electrolytes. CRC Press; 1992.

[45] Abhat A. Low temperature latent heat thermal energy storage: heat storage materials. Sol Energy Jan. 1983;30(4):313-32.

[46] Alawadhi EM, Alqallaf HJ. Building roof with conical holes containing PCM to reduce the cooling load: numerical study. Energy Convers Manag Aug. 2011;52(8-9):2958-64. 